\title{
Single-seed oxygen consumption measurements and population-based threshold models link respiration and germination rates under diverse conditions
}

\author{
Pedro Bello and Kent J. Bradford* \\ Seed Biotechnology Center, Department of Plant Sciences, University of California, Davis, CA 95616-8780, USA
}

(Received 16 May 2016; accepted after revision 20 July 2016)

\begin{abstract}
Seed germination is responsive to diverse environmental, hormonal and chemical signals. Germination rates (i.e. speed and distribution in time) reveal information about timing, uniformity and extent of germination in seed populations and are sensitive indicators of seed vigour and stress tolerance. Population-based threshold (PBT) models have been applied to describe germination responses to temperature, water potential, hormones, ageing and oxygen. However, obtaining detailed data on germination rates of seed populations requires repeated observations at frequent times to construct germination time courses, which is labour intensive and often impractical. Recently, instruments have been developed to measure repeatedly the respiration (oxygen consumption) of individual seeds following imbibition, providing complete respiratory time courses for populations of individual seeds in an automated manner. In this study, we demonstrate a new approach that enables the use of single-seed respiratory data, rather than germination data, to characterize the responses of seed populations to diverse conditions. We applied PBT models to single-seed respiratory data and compared the results to similar analyses of germination time courses. We found consistent and quantitatively comparable relationships between seed respiratory and germination patterns in response to temperature, water potential, abscisic acid, gibberellin, respiratory inhibitors, ageing and priming. This close correspondence between seed respiration and germination time courses enables the use of semi-automated respiratory measurements to assess seed vigour and quality parameters. It also raises intriguing questions about the fundamental relationship between the respiratory capacities of seeds and the rates at which they proceed toward completion of germination.
\end{abstract}

\footnotetext{
* Correspondence

Email: kjbradford@ucdavis.edu
}

Keywords: germination rate, oxygen consumption, population-based threshold models, respiration, vigour

\section{Introduction}

Respiration is among the earliest metabolic processes initiated following hydration of a dry seed (Hourmant and Pradet, 1981). The physiological and cellular processes required to repair damage accumulated in the dry state and to subsequently transcribe RNAs, translate proteins and support embryo growth required for completion of germination depend upon the production of ATP and reductants via oxidative mitochondrial respiration (Bewley et al., 2013). It has long been known that seed quality, as indicated in particular by the speed and percentage of germination in a seed population, is associated with respiratory capacity (Woodstock and Grabe, 1967), and some tests of seed vigour and viability (e.g. the tetrazolium staining test and ethanol production) are based upon this relationship (Woodstock, 1973; Rutzke et al., 2008; Buckley and Huang, 2011; Kodde et al., 2012). The seed biology and technology community is constantly seeking to develop and optimize improved methods to assess seed quality and parameters in a rapid, cost-effective and replicable manner (ISTA, 2010; Matthews et al., 2012), but most methods still rely on evaluating germination itself (radicle emergence and/or seedling growth) as the primary standard rather than associated metabolic processes such as respiration. This is partly because methods to measure seed respiration are relatively inconvenient, relying on gas chromatographic or electrode measurements of changes in headspace gases in sealed containers (e.g. Dahal et al., 1996; Edelstein and Welbaum, 2011) or flow-through gas exchange systems (Patane and Avola, 2013). In addition, these are generally not sensitive enough to detect oxygen consumption of individual seeds, and therefore depend on measurements of pooled seed samples, which can only give average values for the entire 
population. Such averages are relatively insensitive measures for population parameters, and cannot reveal the underlying physiological variation among individual seeds, tissues or cells (Still and Bradford, 1997; Trewavas, 2012).

Recently, a technology has been developed that enables measurement of oxygen consumption of individual seeds at frequent intervals over time. The so-called Q2 instrument (www.astec-global.com) measures oxygen consumption of relatively large numbers of individual seeds (up to 1536) automatically with repeated sampling over time after imbibition. Seeds are imbibed on agar in sealed microtitre plate wells or screw-cap vials and, as they consume the oxygen in the wells, the fluorescence of an oxygen-sensitive dye in the top of the well is monitored periodically by a sensor to measure changes in oxygen concentration (Draaijer et al., 1999; Van Duijn and Konig, 2001). The robotic sensor head can measure samples on an hourly basis and the shapes of resulting oxygen depletion curves can be analysed for a number of parameters (termed ASTEC values) using the Q2 software. Correlations observed between these respirationrelated parameters and seed germination characteristics indicate that Q2 tests could enable the use of oxygen consumption rates as indirect indicators of seed vigour and quality (Van Asbrouck and Taridno, 2009; Zhao and Zhong, 2012; Bradford et al., 2013; Zhao et al., 2013).

However, current analyses applied to individual seed oxygen consumption rates rely primarily on averaging such data, along with statistical estimates of variation within the seed population for certain parameters (Bradford et al., 2013). These analyses therefore do not take full advantage of the ability to measure the oxygen consumption of individual seeds and extract population-based parameters from that information. It might be thought that such individual variation would make the results difficult to interpret without averaging, but as Eric Roberts (1973) insightfully noted, 'It has been suggested that seeds are unpredictable things and consequently it would be a waste of time to try to perceive laws of behavior among such erratic individuals .... But other disciplines have shown us quite clearly that, although the behavior of any individual in a population may be quite unpredictable, the behavior of populations of individuals can often be defined very accurately.' This was confirmed by subsequent development of population-based models of seed viability loss during storage (Ellis and Roberts, 1981), and population-based threshold (PBT) models analysing the timing of radicle emergence in seed populations have proven to be very powerful in describing and quantifying seed behaviour in response to a wide range of environmental and hormonal conditions (e.g. Gummerson, 1986; Bradford, 1990; Bradford et al., 1993, 2007; Ni and Bradford, 1993; Dahal and
Bradford, 1994; Alvarado and Bradford, 2002; FinchSavage, 2004; Finch-Savage and Leubner-Metzger, 2006). The germination rates (inverse of the times to germination) of seeds are among the most sensitive indicators of seed vigour, but as obtaining such data generally requires repeated and closely spaced observations, they are seldom applied except for research purposes (Matthews and Powell, 2011). Image analysis methods that semi-automate the data collection process have improved this situation (Joosen et al., 2010) but an analyst is still required to conduct the image capture for each sample at frequent times.

The ability of the Q2 instrument to collect repeated, closely spaced measurements of individual seed oxygen consumption rates provides an opportunity to test whether such data could be analysed by the PBT models that have been applied to germination time courses. If so, such analyses could reveal fundamental relationships between respiration rates and germination rates and how they are influenced by conditions that affect seed germination performance, including temperature, water potential, hormones, ageing or priming. Here, we introduce a novel method for presenting Q2 oxygen consumption data that enables direct analysis using existing PBT models, allowing derivation of quantitative parameters relating to seed quality and predictions of seed performance under a wide range of conditions. We also provide a spreadsheet that can accept data directly from the Q2 instrument and analyse it according to our new approach. Our results confirm for the first time that seed oxygen consumption rates on an individual seed and population basis are highly correlated with germination timing across a wide range of conditions that affect seed germination rates. The automated Q2 measurements could substitute for labour-intensive germination timecourse observations, making this sensitive measure of seed quality more feasible and practical for seed vigour assessments. Our results also provide insight into how seed metabolic rates, as indicated by oxygen consumption rates, relate to the timing of the physiological processes required for the completion of germination and initiation of seedling growth.

\section{Materials and methods}

\section{Q2 and germination tests}

Protocols for Q2 measurements were essentially as described previously (Bradford et al., 2013). Seeds were placed on agar $(0.5-1 \% \mathrm{w} / \mathrm{v})$ pipetted into Q2 plates or vials. Microtitre plates (96-well; individual well volume of $400 \mu \mathrm{l}$ ) were utilized for tomato (Solanum lycopersicum L. cv. Moneymaker) and lettuce (Lactuca sativa L. cv. Salinas) seeds, with agar volumes of 250 (tomato) and $150 \mu$ l (lettuce). Screw-cap vials 


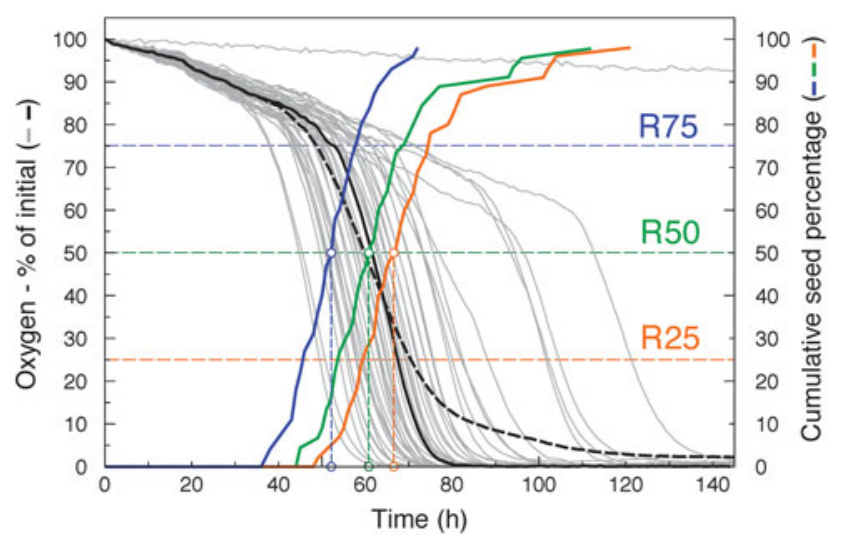

Figure 1. Example of the generation of population oxygen depletion (POD) curves for tomato seeds imbibed at $25^{\circ} \mathrm{C}$. Initial oxygen percentage is normalized to $100 \%$ (equivalent to $21 \%$ air composition) and each grey curve indicates the oxygen consumption time course of an individual seed. The coloured lines indicate the cumulative percentages of individual seeds over time that have reduced the oxygen contents of sealed wells (or vials) to $75 \%$ (R75 - solid blue line), 50\% (R50 - solid green line) and 25\% (R25 - solid orange line) of the original level. The coloured circles on the time axis indicate the median times required by the population of individual seeds to reduce oxygen levels to 75, 50 and $25 \%$ of the initial value (R75(50), R50(50) and R25(50) values, respectively). Time courses can also be constructed based on other oxygen consumption percentages. Black lines represent the median (solid) and average (dashed) oxygen depletion time courses for the entire seed population.

(total volume of $800 \mu \mathrm{l}$ ) with $375 \mu \mathrm{l}$ of agar were utilized for radish seeds (Raphanus sativus L. cv. Red Satin). A minimum of 95 seeds per lot was tested for tomato and lettuce and 48 seeds per lot for radish; actual numbers of seeds tested in each experiment are given below. When multiple replicate plates were used for a given treatment condition, the data were converted to population oxygen depletion curves (see Fig. 1) and percentages of seeds for a specific oxygen depletion level at a given observation time were averaged across all replicates for the time-course plots shown that also were used for modelling. Germination (radicle emergence) was scored periodically in the plates or vials during the measurements in the Q2 instrument so that both the time to radicle emergence and the oxygen consumption pattern were known for individual seeds. Germination data for a given observation time were averaged across replicates.

\section{Temperature}

Our Q2 instrument has a custom-built temperaturecontrol system using Peltier heating/cooling units and fans that enabled temperature to be controlled to $\pm 0.5^{\circ} \mathrm{C}$, as confirmed with thermocouples placed in the agar of the wells. A total of 288 tomato seeds (three 96-well plates) were utilized in Q2 tests at each temperature reported.

\section{Water potential}

Media of specific $\Psi$ values were prepared with agar and PEG400 (Money, 1989), as use of larger molecular weight PEG (e.g. PEG8000) prevented setting of the agar. Final water potentials of the prepared media were measured using a Wescor Vapro osmometer (Wescor Inc., Logan, Utah, USA). A total of 288 tomato seeds (three 96-well plates) were utilized in Q2 tests for each water-potential treatment reported.

\section{Respiratory inhibitors}

Different concentrations of potassium cyanide (KCN) or salicylhydroxamic acid (SHAM) were used to inhibit oxidative respiration through the cyanide-sensitive and cyanide-insensitive pathways. Tests were conducted in $800-\mu \mathrm{l}$ screw-cap vials with dilute agar $(0.5 \mathrm{w} / \mathrm{v} ; 400 \mu \mathrm{l})$ containing $0.1-0.3 \mathrm{mM} \mathrm{KCN}$ or $0.5-3 \mathrm{mM}$ SHAM. A total of 48 tomato seeds (one 48-vial plate) were utilized in Q2 tests for each inhibitor concentration.

\section{Priming and accelerated ageing}

A single lot of lettuce seeds (cv. Salinas) was subjected either to priming to advance germination or to accelerated ageing to delay germination. Priming was conducted by imbibing seeds on blotters saturated with $-1.25 \mathrm{MPa}$ PEG8000 for $2 \mathrm{~d}$ under fluorescent light at $9^{\circ} \mathrm{C}$, followed by rinsing and drying. Accelerated ageing was achieved by equilibrating seeds at $75 \%$ relative humidity $(\mathrm{RH})$ for $4 \mathrm{~d}(11.3 \%$ moisture content, dry weight basis) at room temperature (approximately $23^{\circ} \mathrm{C}$ ) followed by sealing in small airtight vials and incubating at $50^{\circ} \mathrm{C}$ for 2,4 or $6 \mathrm{~d}$. Seeds were then measured in the Q2 at $25^{\circ} \mathrm{C}$. A total of 95 lettuce seeds were utilized in Q2 tests (one 96-well plate) for each treatment.

\section{Controlled deterioration}

Radish (R. sativus) seeds were subjected to controlled deterioration by equilibrating at 33\% RH (over saturated $\mathrm{MgCl}_{2} ; 4.78 \%$ moisture content, dry weight basis) for $7 \mathrm{~d}$ at room temperature (approximately $23^{\circ} \mathrm{C}$ ) followed by sealing in foil packets and incubating at $50^{\circ} \mathrm{C}$ for a total of 4 months, during which time germination tests were performed on subsamples every 7-14 d. Subsamples were collected after 0, 45, 66 and $80 \mathrm{~d}$ of ageing and stored at $-20^{\circ} \mathrm{C}$. Q2 tests were conducted simultaneously on these samples at $25^{\circ} \mathrm{C}$ 
using $800-\mu \mathrm{l}$ vials containing $300 \mu \mathrm{l}$ of agar. A total of 48 seeds were utilized in Q2 tests (one 48-vial plate) for each ageing treatment and double the amount of seeds was tested for the control treatment.

\section{Results}

\section{Population-based analyses of single-seed oxygen consumption rates}

While seed oxygen consumption data from the Q2 instrument can be analysed by focusing on the shapes of the individual oxygen depletion time courses (Bradford et al., 2013), we introduce here a novel approach to visualize the variation in respiratory patterns among seeds (see subsequent sections for evidence that respiratory activity accounts for most seed oxygen consumption). We convert the oxygen depletion time courses of the individual seeds in the measured population into a cumulative curve based on the time required for each seed to reduce the oxygen in the Q2 well to a specific percentage of the initial value. This initial oxygen concentration $(21 \%$ in the air) is normalized to $100 \%$ based on the first measurement for each individual well or vial. The time at which each seed reduces the oxygen concentration to that percentage can be plotted as a cumulative percentage curve versus the time of imbibition (Fig. 1). The resulting time course of respiratory activity is analogous to a germination time course, which is a cumulative plot over time of when each seed achieves the end point of radicle emergence. These population oxygen depletion (POD) curves provide a simple and convenient way to compare the effects of various treatments on the distribution of respiration rates in the measured seed population. A spreadsheet accepting data exported from the Q2 instrument and converting it to POD curves is available from the supplementary file Spreadsheet S1. This approach takes advantage of the ability of the Q2 instrument to collect data for each individual seed and utilizes all of the data for analyses, rather than only means or medians of the population (Fig. 1). Unlike other derived parameters based on the shapes of the original oxygen depletion time courses (Bradford et al., 2013), the POD curves are visually similar to germination time courses and are therefore familiar to seed biologists and technologists.

Varying the percentage of the oxygen depletion selected results in somewhat different shapes of these cumulative curves (Fig. 1). For convenience and illustrative purposes, we use $75 \%$ (R75), 50\% (R50) and $25 \%$ (R25) of the initial oxygen remaining, but the percentage of oxygen depletion used can be varied as long as it is applied consistently across all seeds. Of course, greater oxygen depletions mean lower oxygen percentages remaining in the vials, which itself can reduce respiration rates and delay or prevent germination. As this is a closed-system test, essentially all of the oxygen is eventually consumed. However, for many species, germination was not affected greatly until the percentage of oxygen in air was less than $\sim 5 \%$ (Bradford et al., 2007), corresponding to approximately $25 \%$ of the initial oxygen concentration ( $21 \%$ ) remaining. In general, the R50 level of oxygen depletion provides the median response of the population, while less or greater depletion levels can be used to reduce the duration of the test (R75) or to better match germination time courses in some cases (R25; see below). By selecting the appropriate oxygen depletion percentage value, time courses and treatment differences that closely resemble those among germination time courses can be generated. In addition, as we show below, the POD curves can be analysed using the same PBT models that have been applied to germination time courses.

\section{Germination and respiration responses to temperature (thermal time model)}

Temperature has a primary influence on both the capacity for germination in dormant seeds and the rate or speed of germination in non-dormant seeds (Bewley et al., 2013; Batlla and Benech-Arnold, 2015). Three cardinal temperatures (minimum, optimum and maximum) describe the range of temperatures over which seeds of a particular species can germinate (Alvarado and Bradford, 2002). Germination rates (the inverse of time to a specific percentage germination in the total population, i.e. $1 / t_{50}$ for $50 \%$ germination) generally increase linearly between the minimum or base temperature $\left(T_{\mathrm{b}}\right)$ and the optimum temperature $\left(T_{\mathrm{o}}\right)$, as in the degree-days or thermal time model, $\theta_{T}(g)=$ $\left(T-T_{\mathrm{b}}\right) t_{g}$, where $\theta_{T}(g)$ is the thermal time required from imbibition until radicle emergence of fraction or percentage $g$ and $T$ is the temperature at which the seeds are imbibed. The thermal time model has been applied extensively to describe seed germination timing in response to temperature (Bierhuizen and Wagenvoort, 1974; Garcia-Huidobro et al., 1982; Covell et al., 1986; Dahal et al., 1990; Alvarado and Bradford, 2002). Since all seeds in a population do not germinate simultaneously, germination rates of seed populations (rather than of specific percentages) can be analysed by transforming the cumulative germination percentages to probits and plotting versus a log time scale (Covell et al., 1986; Dahal et al., 1990). This can be described according to equation (1):

$$
\operatorname{probit}(g)=\left\{\log \left[\left(T-T_{\mathrm{b}}\right) t_{g}\right]-\log \theta_{T}(50)\right\} / \sigma_{\theta T}
$$

where probit $(g)$ is the germination fraction transformed into probits and $\sigma_{\theta T}$ is the standard deviation 
of thermal times to germination among seeds in the population. Germination time courses at different temperatures will be linearized when probit $(g)$ is plotted versus $\log t_{g}$. $\log \theta_{T}(50)$ is where the resulting line crosses $50 \%$ germination (probit $(50)=0$ ), and the inverse of the slope is $\sigma_{\theta T}$, the standard deviation of log thermal time requirements among seeds. Repeated regressions using different $T_{\mathrm{b}}$ values are used to optimize the best fit between probit $(g)$ and the $\log$ of $\theta_{T}(g)$, which is generally normally distributed within the population (Dahal et al., 1990). The model can also be fit using programs that optimize the variables in equation (1) (Chantre et al., 2009) or by other statistical methods (Hay et al., 2014; Hardegree et al., 2015).

To compare respiration and germination rates across temperatures, tomato (S. lycopersicum) seeds were imbibed on agar in sealed wells in the Q2 instrument at constant 15,20 and $25^{\circ} \mathrm{C}$. At each temperature tested, the seeds exhibited an initial relatively slow rate of respiration, followed by a transition to a phase of more rapid of respiration until it again slowed as oxygen concentrations became limiting, as illustrated for $25^{\circ} \mathrm{C}$ (Fig. 1). Overall shapes of oxygen depletion curves were similar for all germinating seeds, with the differences among seeds due primarily to the times at which oxygen consumption transitioned from the slow initial respiration rate to the more rapid second phase (Fig. 1). In the case of tomato seeds, this transition coincides closely with the time of radicle emergence (Bradford et al., 2013). Dead seeds did not exhibit significant oxygen consumption, with final oxygen levels after $150 \mathrm{~h}$ remaining above $90 \%$ of the initial value (e.g. top grey line in Fig. 1), and dormant seeds have lower and often declining rates of oxygen consumption (see the hormone section below). These characteristics of the individual seed and population respiratory patterns have been analysed previously using ASTEC values that focus on the shapes of the individual oxygen depletion time courses (Zhao and Zhong, 2012; Bradford et al., 2013; Zhao et al., 2013).

When median oxygen depletion patterns of tomato seed populations were compared at different temperatures, oxygen consumption was delayed as temperature decreased (Fig. 2A). Temperature affected both initial and secondary respiration rates similarly, slowing both phases of respiration at lower temperatures and increasing them at warmer temperatures (Fig. 2A). This is reflected in increasing median slopes [starting metabolism rate (SMR) and oxygen metabolism rate (OMR) values] of oxygen depletion curves and earlier transitions between initial and secondary respiration rates [increasing metabolism time (IMT) values] as temperatures increased (see supplementary Table S1). Times to radicle emergence in the Q2 wells were observed at intervals (Fig. 3A) and POD curves were developed based on the times required for individual seeds to deplete the oxygen in their wells to 75,50 and $25 \%$ of the initial amount at the different temperatures (Fig. 3B, C and D, respectively). Times to germination increased as temperature decreased, but $93 \%$ of seeds completed germination even at the lowest temperature (Fig. 3A, supplementary Table S1). POD curves at 75,50 and $25 \%$ oxygen remaining exhibited relationships across temperatures very similar to those for radicle emergence (Fig. 3A-D). As respiration data are available for every seed rather than only being registered at periodic observations, the greater density of data points is evident for the POD curves compared to the germination time courses.

The thermal time model for suboptimal temperatures was used to calculate the $T_{\mathrm{b}}$ values for both germination and respiration (R75, R50 and R25 POD curves; Table 1) and time courses were predicted from the model using the resulting parameter values (solid lines in Fig. 3A-D). The thermal time model fitted both germination and respiration time courses extremely well, with $r^{2}$ values of 0.916 for germination and from 0.974 to 0.944 for POD curves (Table 1 ; supplementary Fig. S1A-D). Similarly, the times to $50 \%$ germination $\left(t_{50}\right)$ were highly correlated to the times required for $50 \%$ of seeds to deplete oxygen in the wells to specific levels at each temperature (Fig. 4A, open symbols). The $T_{\mathrm{b}}$ values estimated from the thermal time model were slightly higher for germination $\left(6.6^{\circ} \mathrm{C}\right)$ than for respiration $\left(2.2-4^{\circ} \mathrm{C}\right)$ (Table 1$)$, as might be expected if respiration could continue at slow rates even at low temperatures at which germination would not be completed. As values from the thermal time model based on the R75 POD curves were highly correlated with actual germination timing $\left(r^{2}=\right.$ 0.93; Fig. 4A), seed respiration rates even quite early in the oxygen consumption time course are highly predictive of the effects of temperature on rates of radicle emergence.

\section{Germination and respiration responses to water potential (hydrotime model)}

Seed germination rates are very sensitive to water potential $(\Psi)$, exhibiting a linear decline (i.e. delay) with even small decreases in $\Psi$ (Gummerson, 1986; Bradford, 1990). Unlike the $T_{\mathrm{b}}$, which in the simplest case is assumed to be constant among all seeds in a population, the $\Psi_{\mathrm{b}}$ values differ among seeds, such that some can germinate to lower $\Psi$ than others (Gummerson, 1986). The $\Psi$ that just prevents germination of a specific fraction of the seed population $(g)$ is termed the base water potential for that fraction, or $\Psi_{\mathrm{b}}(g)$. The $\Psi_{\mathrm{b}}(g)$ values are generally normally distributed within the population and inversely related to $t_{g^{\prime}}$ resulting in a hydrotime model of the form $\theta_{\mathrm{H}}=(\Psi-$ $\left.\Psi_{\mathrm{b}}(g)\right) t_{g}$, indicating that all seeds in the population 

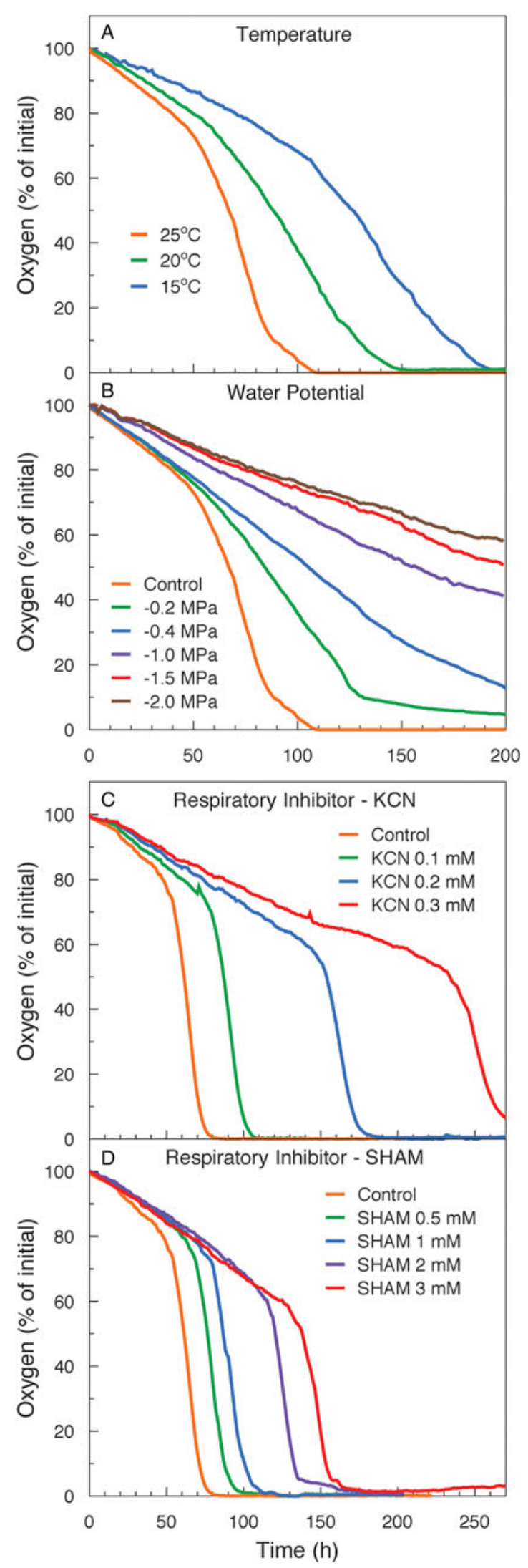

Figure 2. Median oxygen depletion curves of: (A) tomato seeds imbibed at temperatures of $25^{\circ} \mathrm{C}$ (orange), $20^{\circ} \mathrm{C}$ (green) or $15^{\circ} \mathrm{C}$ (blue) at $0 \mathrm{MPa}$; (B) tomato seeds imbibed at water potentials of $0 \mathrm{MPa}$ (orange), $-0.2 \mathrm{MPa}$ (green), $-0.4 \mathrm{MPa}$ require the same accumulated hydrotime $\left(\theta_{\mathrm{H}}\right)$ to complete germination but vary in their thresholds for responding to $\Psi$. Germination rates of seed populations imbibed at different $\Psi$ (at a constant single temperature) can be analysed by repeated regression by plotting probit $(g)$ versus $\Psi-\left(\theta_{\mathrm{H}} / t_{g}\right)$, according to equation (2):

$$
\operatorname{probit}(g)=\left[\Psi-\left(\theta_{\mathrm{H}} / t_{g}\right)-\Psi_{\mathrm{b}}(50)\right] / \sigma_{\Psi \mathrm{b}}
$$

where $\sigma_{\Psi \mathrm{b}}$ is the standard deviation of the distribution of $\Psi_{\mathrm{b}}(g)$, which is assumed to be normally distributed (Bradford, 1990). The model parameters are optimized by varying $\theta_{\mathrm{H}}$ values until the highest $r^{2}$ for the regression is obtained. $\Psi_{\mathrm{b}}(50)$ is determined as the value at which the probit regression line crosses zero, and $\sigma_{\Psi \mathrm{b}}$ is the inverse of the slope (Bradford, 1990, 2002; Bradford and Still, 2004).

It was shown previously that average respiration rates of pooled tomato seed samples fell as $\Psi$ decreased (Dahal et al., 1996). We re-examined this relationship using single-seed respiration measurements of tomato seeds in the Q2. At the higher $\Psi$ range ( 0 to -0.4 $\mathrm{MPa})$, germination speed was delayed, as expected, although final germination percentages remained above $80 \%$ (Fig. 3E). Median oxygen depletion rates were also slower and the sharp transition to a more rapid rate disappeared as $\Psi$ was reduced (Fig. 2B). At low $\Psi$, oxygen depletion rates remained essentially linear at the initial rate, which, in contrast to results obtained with temperature, were less affected by increasing water stress in this higher $\Psi$ range (see supplementary Table S1). At lower water potentials at which radicle emergence was prevented ( $\Psi \leq-1.0 \mathrm{MPa})$ (Fig. 3E), initial respiration rates were slower and remained linear for up to $150 \mathrm{~h}$ (Fig. 2B, supplementary Table S1), consistent with previous reports (Dahal et al., 1996). This pattern is also consistent with the transition to a more rapid respiration rate in tomato seeds being associated with radicle emergence (Bradford et al., 2013), although radicle emergence still occurred at $-0.4 \mathrm{MPa}$ (Fig. 3E) without such a change in median oxygen depletion rate (Fig. 2B).

When expressed as POD curves, delays in respiration between 0 and $-0.4 \mathrm{MPa}$ were small but detectable at the higher R75 oxygen threshold level and became clearly evident at the R50 and R25 depletion

(blue), $-1.0 \mathrm{MPa}$ (purple), $-1.5 \mathrm{MPa}$ (red) or $-2.0 \mathrm{MPa}$ (brown) at $25^{\circ} \mathrm{C}$; (C) tomato seeds imbibed in concentrations of the respiratory inhibitor $\mathrm{KCN}$ of $0 \mathrm{mM}$ (control; orange), $0.1 \mathrm{mM}$ (green), $0.2 \mathrm{mM}$ (blue) or $0.3 \mathrm{mM}$ (red) at $25^{\circ} \mathrm{C}$; (D) tomato seeds imbibed in concentrations of the respiratory inhibitor SHAM of $0 \mathrm{mM}$ (control; orange), $0.05 \mathrm{mM}$ (green), $1 \mathrm{mM}$ (blue), $2 \mathrm{mM}$ (purple) or $3 \mathrm{mM}$ (red) at $25^{\circ} \mathrm{C}$. All seeds in the test populations were used to calculate median curves, regardless of their germination status. 


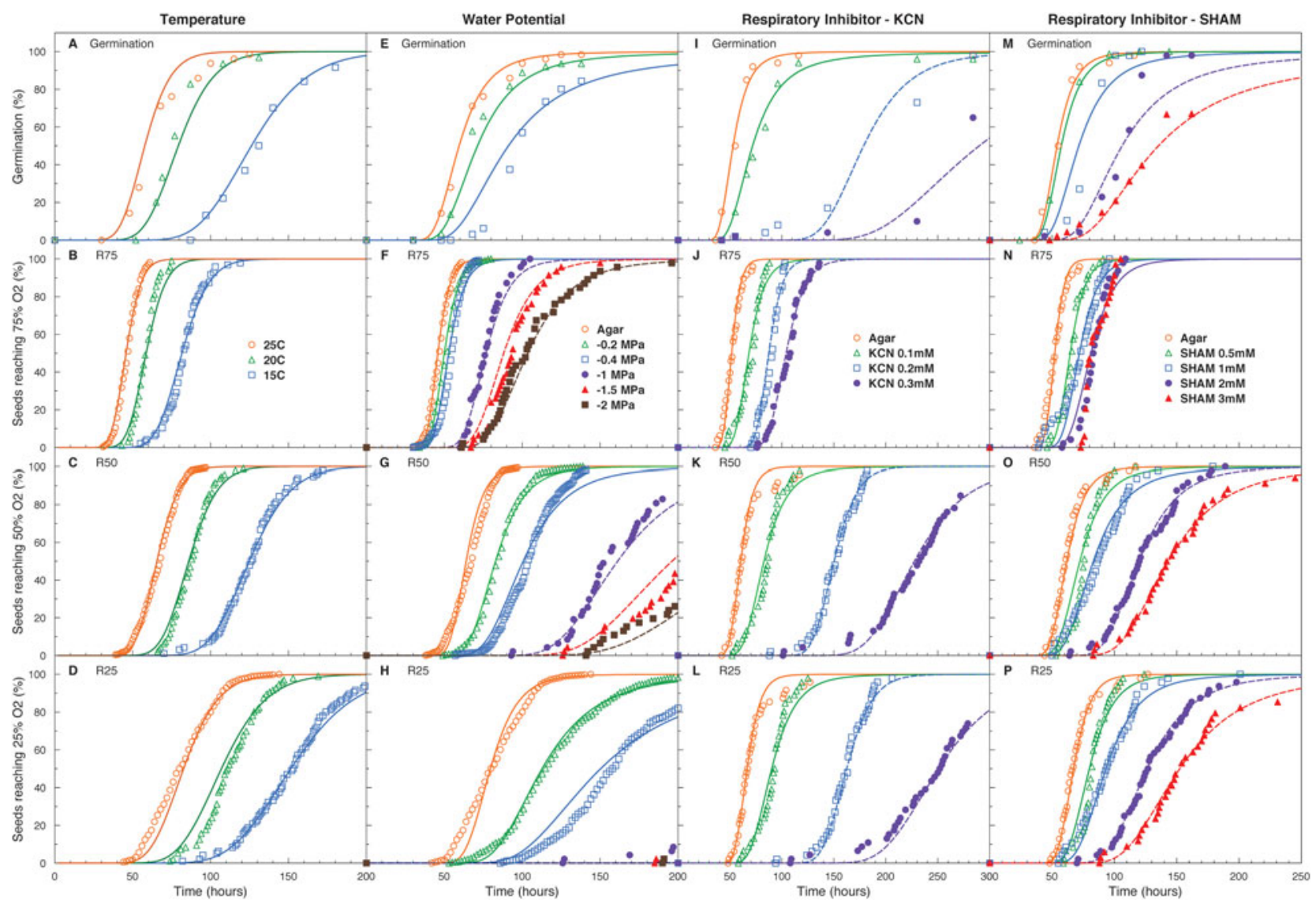

Figure 3. Germination time courses (A, E, I and M) and R75, R50 and R25 population oxygen depletion (POD) time courses (B-D, F-H, J-L and N-P) of tomato seeds imbibed under different conditions. Cumulative germination (A) and POD time courses (B, C, D) are shown for seeds imbibed on agar at $25^{\circ} \mathrm{C}$ (orange circles), $20^{\circ} \mathrm{C}$ (green triangles) or $15^{\circ} \mathrm{C}$ (blue squares). Cumulative germination (E) and POD time courses (F, G, H) are shown for seeds imbibed at $25^{\circ} \mathrm{C}$ on agar at $0 \mathrm{MPa}$ (open orange circles), $-0.2 \mathrm{MPa}$ (open green triangles), $-0.4 \mathrm{MPa}$ (open blue squares), $-1 \mathrm{MPa}$ (filled purple circles), $-1.5 \mathrm{MPa}$ (filled red circles) or $-2 \mathrm{MPa}$ (filled brown circles). Cumulative germination (I) and POD time courses (J, K, L) of seeds imbibed at $25^{\circ} \mathrm{C}$ on agar containing 0 (control, open orange circles), $0.1 \mathrm{mM}$ (open green triangles), $0.2 \mathrm{mM}$ (open blue squares) or $0.3 \mathrm{mM}$ (filled purple circles) KCN. Cumulative germination (M) and POD time courses (N, O, P) of seeds imbibed at $25^{\circ} \mathrm{C}$ on agar containing 0 (control, open orange circles), $0.5 \mathrm{mM}$ (open green triangles), $1 \mathrm{mM}$ (open blue squares), $2 \mathrm{mM}$ (filled purple circles) or $3 \mathrm{mM}$ (filled red triangles) SHAM. Continuous curves are predicted by fitting the appropriate population-based threshold model to the data across the temperature, water potential, KCN or SHAM ranges (Table 1). Solid and dashed curves indicate where two different models were fit to sub-components of the data (see text).

levels (Figs 3F-H). Initial respiration rates (indicated by R75) declined further at lower $\Psi$ at which germination was prevented, and responded quantitatively as $\Psi$ was decreased (Fig. 3F). At R50 and R25 levels of oxygen depletion, decreasing respiration rates were more evident, such that only a few seeds attained the R25 depletion level at $-1 \mathrm{MPa}$ and lower (Fig. 3G, H; see also Fig. 2B). The hydrotime model accounted well for the effects of increasing water stress between 0 and -0.4 $\mathrm{MPa}$ on both germination and respiration (Fig. 3E-H, solid curves; Table 1). There was a close linear correlation between germination $t_{50}$ values and median times to R75, R50 or R25 based on POD curves across these $\Psi$ values (Fig. 4A, closed symbols); this relationship was essentially identical to that for temperature, as noted previously (Dahal et al., 1996). While respiration proceeded at and below $-1.0 \mathrm{MPa}$ with POD curves similar to those at higher $\Psi$ (Fig. 3F, G), data across the entire $\Psi$ range from 0 to $-2.0 \mathrm{MPa}$ could not be fit satisfactorily using a single hydrotime model. This was also reported for germination rates of tomato seeds across a wide range of $\Psi$ (Dahal et al., 1990; Ni and Bradford, 1992; Dahal and Bradford, 1994) and has been addressed by separating the data into high and low $\Psi$ ranges and fitting the hydrotime model separately to data for each group of $\Psi$ values. That approach demonstrated that seeds initially imbibed at inhibitory $\Psi$ levels adjusted by lowering their $\Psi_{\mathrm{b}}$ values and then progressed toward completion of germination in accordance with that new $\Psi_{\mathrm{b}}(g)$ distribution. When we fit the hydrotime model to the POD curves separately for data from 0 to $-0.4 \mathrm{MPa}$ and from -1.0 to $-2.0 \mathrm{MPa}$, the models fit each dataset well (Table 1; supplementary Fig. S1F, G) 
Table 1. Model parameters and probit regressions for the PBT models describing germination and respiration

\begin{tabular}{|c|c|c|c|c|c|c|c|}
\hline \multirow{2}{*}{$\begin{array}{l}\text { Model and species } \\
\text { Thermal time - tomato }\end{array}$} & \multicolumn{4}{|c|}{ Model parameters } & \multicolumn{3}{|c|}{ Probit regression parameters } \\
\hline & $\begin{array}{l}\theta_{T}(50) \\
\left({ }^{\circ} \mathrm{C} \mathrm{h}\right)\end{array}$ & & $\begin{array}{c}T_{\mathrm{b}} \\
\left({ }^{\circ} \mathrm{C}\right)\end{array}$ & $\begin{array}{c}\sigma_{\theta T} \\
\left({ }^{\circ} \mathrm{C} \mathrm{h}\right)\end{array}$ & Slope & $Y(x=0)$ & $r^{2}$ \\
\hline Germination & 3.03 & & 6.55 & 0.098 & 10.2 & -30.8 & $0.916^{* * *}$ \\
\hline R75 & 3.02 & & 2.23 & 0.064 & 15.7 & -47.5 & $0.973^{* * *}$ \\
\hline $\mathrm{R} 50$ & 3.14 & & 3.95 & 0.073 & 13.8 & -43.2 & $0.967^{* * *}$ \\
\hline $\mathrm{R} 25$ & 3.25 & & 3.24 & 0.092 & 10.9 & -35.4 & $0.944^{* * *}$ \\
\hline Hydrotime - tomato & $\begin{array}{c}\theta_{\mathrm{H}} \\
(\mathrm{MPa} \mathrm{h})\end{array}$ & & $\begin{array}{l}\Psi_{\mathrm{b}}(50) \\
(\mathrm{MPa})\end{array}$ & $\begin{array}{c}\sigma_{\Psi b} \\
(\mathrm{MPa})\end{array}$ & & & \\
\hline Germination & 69.0 & & -1.15 & 0.270 & 3.73 & 4.28 & $0.898^{* * *}$ \\
\hline R75 - High & 139 & & -3.03 & 0.400 & 2.48 & 7.52 & $0.969^{* * *}$ \\
\hline R75 - Low & 297 & & -4.87 & 0.620 & 1.62 & 7.90 & $0.945^{* * *}$ \\
\hline R50 - High & 70.4 & & -1.10 & 0.153 & 6.56 & 7.24 & $0.931^{* * *}$ \\
\hline R50 - Low & 447 & & -3.81 & 0.706 & 1.42 & 5.39 & $0.865^{* * *}$ \\
\hline R25 - High & 65.5 & & -0.83 & 0.150 & 6.68 & 5.53 & $0.898^{* * *}$ \\
\hline Hydrothermal time - tomato & $\begin{array}{c}\theta_{\mathrm{HT}} \\
\left({ }^{\circ} \mathrm{C} \mathrm{MPa} \mathrm{h}\right)\end{array}$ & $\begin{array}{l}T_{\mathrm{b}} \\
\left({ }^{\circ} \mathrm{C}\right)\end{array}$ & $\begin{array}{l}\Psi_{\mathrm{b}}(50) \\
(\mathrm{MPa})\end{array}$ & $\begin{array}{c}\sigma_{\Psi b} \\
(\mathrm{MPa})\end{array}$ & & & \\
\hline Germination & 1230 & 6.55 & -1.15 & 0.26 & 3.91 & 4.51 & $0.861^{* * *}$ \\
\hline R75 - High & 2040 & 2.23 & -1.97 & 0.28 & 3.62 & 7.15 & $0.817^{* * *}$ \\
\hline R75 - Low & 5330 & 2.23 & -4.22 & 0.57 & 1.76 & 7.43 & $0.838^{* * *}$ \\
\hline R50 - High & 1560 & 3.95 & -1.14 & 0.16 & 6.43 & 7.34 & $0.855^{* * *}$ \\
\hline R50 - Low & 6830 & 3.95 & -3.12 & 0.66 & 1.50 & 4.69 & $0.752^{* * *}$ \\
\hline R25 - High & 1470 & 3.24 & -0.84 & 0.14 & 7.15 & 5.98 & $0.856^{* * *}$ \\
\hline Dosage - ABA $-s i t^{w}$ tomato & $\begin{array}{c}\theta_{\mathrm{ABA}} \\
(\log \mu \mathrm{M} h)\end{array}$ & & $\begin{array}{c}\log \operatorname{ABA}_{b}(50) \\
(\log \mu M)\end{array}$ & $\begin{array}{c}\sigma_{\mathrm{ABAb}} \\
(\log \mu \mathrm{M})\end{array}$ & & & \\
\hline Germination & -140 & & 0.68 & 0.58 & -0.549 & 0.681 & $0.950^{* * *}$ \\
\hline $\mathrm{R} 50$ & -187 & & 0.91 & 0.62 & -0.554 & 0.917 & $0.900^{* * *}$ \\
\hline $\mathrm{R} 25$ & -196 & & 0.88 & 0.6 & -0.536 & 0.894 & $0.890^{* * *}$ \\
\hline Dosage - GA - gib1 tomato & $\begin{array}{c}\theta_{\mathrm{GA}} \\
(\log \mu \mathrm{M} h)\end{array}$ & & $\begin{array}{c}\log G_{b}(50) \\
(\log \mu M)\end{array}$ & $\begin{array}{c}\sigma_{\mathrm{GAb}} \\
(\log \mu \mathrm{M})\end{array}$ & & & \\
\hline Germination & 134 & & 0.81 & 0.57 & 0.558 & 0.809 & $0.983^{* * *}$ \\
\hline R75 & 182 & & 0.46 & 0.57 & 0.542 & 0.457 & $0.947^{* * *}$ \\
\hline R50 & 229 & & 0.30 & 0.6 & 0.568 & 0.295 & $0.951^{* * *}$ \\
\hline $\mathrm{R} 25$ & 246 & & 0.27 & 0.59 & 0.561 & 0.261 & $0.951^{* * *}$ \\
\hline Dosage - KCN - Tomato & $\begin{array}{c}\theta_{\mathrm{KCN}} \\
(\log \mathrm{mM} \mathrm{h})\end{array}$ & & $\begin{array}{c}\log \mathrm{KCN}_{\mathrm{b}}(50) \\
(\log \mathrm{mM})\end{array}$ & $\begin{array}{c}\sigma_{\mathrm{KCNb}} \\
(\log \mathrm{mM})\end{array}$ & & & \\
\hline Germination - Low & -61 & & -0.15 & 0.26 & -3.80 & -0.579 & $0.948^{* * *}$ \\
\hline Germination - High & -82 & & -0.24 & 0.09 & -10.7 & -2.58 & $0.895^{*}$ \\
\hline R75 - Low & -84 & & 0.23 & 0.21 & -4.68 & 1.1 & $0.932^{* * *}$ \\
\hline R75 - High & -96 & & 0.40 & 0.13 & -7.77 & 3.08 & $0.960^{* * *}$ \\
\hline R50 - Low & -78 & & -0.03 & 0.23 & -4.33 & -0.147 & $0.932^{* * *}$ \\
\hline R50 - High & -78 & & -0.18 & 0.06 & -16.7 & -3.01 & $0.977^{* * *}$ \\
\hline R25 - Low & -101 & & 0.12 & 0.23 & -4.38 & 0.532 & $0.935^{* * *}$ \\
\hline R25 - High & -81 & & -0.19 & 0.07 & -14.7 & -2.83 & $0.955^{* * *}$ \\
\hline
\end{tabular}




\begin{tabular}{|c|c|c|c|c|c|c|}
\hline Dosage - SHAM - Tomato & $\begin{array}{c}\theta_{\text {SHAM }} \\
(\log \mathrm{mM} h)\end{array}$ & $\begin{array}{c}\log \operatorname{SHAM}_{b}(50) \\
(\log \mathrm{mM})\end{array}$ & $\begin{array}{c}\sigma_{\text {SHAMb }} \\
(\log \mathrm{mM}) \\
\end{array}$ & & & \\
\hline Germination - Low & -88 & 1.23 & 0.34 & -2.90 & 3.57 & $0.847^{* * *}$ \\
\hline Germination - High & -87 & 1.12 & 0.27 & -3.71 & 4.14 & $0.783^{* * *}$ \\
\hline R75 & -190 & 2.64 & 0.43 & -2.33 & 6.17 & $0.906^{* * *}$ \\
\hline R50 - Low & -168 & 2.02 & 0.51 & -1.95 & 3.94 & $0.911^{* * *}$ \\
\hline R50 - High & -128 & 1.37 & 0.22 & -4.50 & 6.18 & $0.981^{* * *}$ \\
\hline R25 - Low & -168 & 1.80 & 0.4 & -2.48 & 4.48 & $0.911^{* * *}$ \\
\hline R25 - High & -130 & 1.33 & 0.23 & -4.44 & 5.89 & $0.985^{* * *}$ \\
\hline Ageing - lettuce & $\begin{array}{c}\theta_{\text {age }} \\
(\mathrm{d} \mathrm{h})\end{array}$ & $\begin{array}{l}p_{\max }(50) \\
(\mathrm{d})\end{array}$ & $\begin{array}{l}\sigma_{p \max } \\
(\mathrm{d})\end{array}$ & & & \\
\hline Germination & 120 & 9.44 & 1.72 & -0.580 & 5.48 & $0.925^{* * *}$ \\
\hline R75 & 272 & 14.3 & 2.79 & -0.346 & 5.04 & $0.951^{* * *}$ \\
\hline $\mathrm{R} 50$ & 358 & 12.4 & 3.11 & -0.295 & 3.93 & $0.917^{* * *}$ \\
\hline $\mathrm{R} 25$ & 449 & 12.3 & 3.96 & -0.266 & 3.12 & $0.943^{* * *}$ \\
\hline Ageing - radish & $\begin{array}{c}\theta_{\text {age }} \\
(\mathrm{d} \mathrm{h})\end{array}$ & $p_{\max }(50)$ & $\begin{array}{l}\sigma_{p \max } \\
(\mathrm{d})\end{array}$ & & & \\
\hline Germination & 1410 & 110 & 16.8 & -0.059 & 6.56 & $0.798^{* *}$ \\
\hline R75 & 4260 & 334 & 38.2 & -0.022 & 6.70 & $0.871^{* * *}$ \\
\hline R50 & 2490 & 146 & 11.5 & -0.081 & 11.7 & $0.909^{* * *}$ \\
\hline R25 & 2660 & 134 & 12.4 & -0.078 & 10.5 & $0.940^{* * *}$ \\
\hline
\end{tabular}

Significance of regressions: ${ }^{*}=P<0.05 ;{ }^{* *}=P<0.01 ;{ }^{* * *}=P<0.001$.

and predicted time courses closely matched the individual seed data in both $\Psi$ ranges (Fig. 3F, G). As had been found for germination (Dahal and Bradford, 1994), incubation at lower $\Psi$ also resulted in a shift in the $\Psi_{\mathrm{b}}$ distribution for respiration to lower values, but once this had occurred, the effects of further reductions in $\Psi$ were consistent with that new distribution. The $\Psi_{\mathrm{b}}(50)$ value for $\mathrm{R} 75$ at high $\Psi$ is $-3.0 \mathrm{MPa}$ but increases to -1.1 and -0.83 for R50 and R25, respectively (Table 1), reflecting the greater sensitivity of the second phase of respiration compared to the initial phase in this $\Psi$ range (Fig. $2 \mathrm{~B}$ ). At the lower $\Psi$ range at which germination was inhibited, respiration continued, but now in relation to lower $\Psi_{\mathrm{b}}(50)$ values of -4.9 and $-3.8 \mathrm{MPa}$ for R75 and R50, respectively (Table 1; experiments were terminated before oxygen was depleted to $25 \%$ for most seeds). Thus, the negative adjustment of $\Psi_{\mathrm{b}}(50)$ values for germination reported previously is also reflected in adjustment to lower $\Psi_{\mathrm{b}}$ thresholds for respiration. Taking this physiological adjustment into account, the models were able to predict quite accurately the effects of increasing water stress not only on germination but also on respiration time courses at high and low ranges of water stress, including those at which germination was completely prevented (Fig. 3E-H). In addition, the $\Psi_{\mathrm{b}}(50)$ values for germination and for R50 were similar $(-1.2 \mathrm{MPa}$ and $-1.1 \mathrm{MPa}$, respectively) (Table 1 ; supplementary Fig. S1E, G). Thus, there is a close relationship between the effects of $\Psi$ on respiration and on germination in the range of $\Psi$ at which germination can be completed (Fig. 4A).

\section{Germination and respiration responses across combined temperatures and water potentials (hydrothermal time model)}

The effects of $T$ and $\Psi$ can be combined to generate the hydrothermal time model that can predict the effects of the combination of those factors (Gummerson, 1986; Dahal and Bradford, 1994). The values of the hydrothermal time constant $\left(\theta_{\mathrm{HT}}\right)$ and $T_{\mathrm{b}}$ are obtained by repeated probit regressions, as described above, to optimize both values, using equation (3):

$$
\operatorname{probit}(g)=\left\{\left[\Psi-\theta_{\mathrm{HT}} /\left(\left(T-T_{\mathrm{b}}\right) t_{g}\right)\right]-\Psi_{\mathrm{b}}(50)\right\} / \sigma_{\Psi \mathrm{b}}
$$

In cases where the thermal and hydrotime models describe the data well and there is limited interaction between their effects (Kebreab and Murdoch, 1999; Bloomberg et al., 2009), the hydrothermal time (HTT) model can be applied (Gummerson, 1986; Dahal and Bradford, 1994; Alvarado and Bradford, 2002). Our results indicate that the HTT model accurately described the germination and respiration behaviour of tomato seeds across all $T$ and $\Psi$ conditions tested (Table 1; supplementary Fig. S2). This allowed all the time-course data across temperatures and at the high 

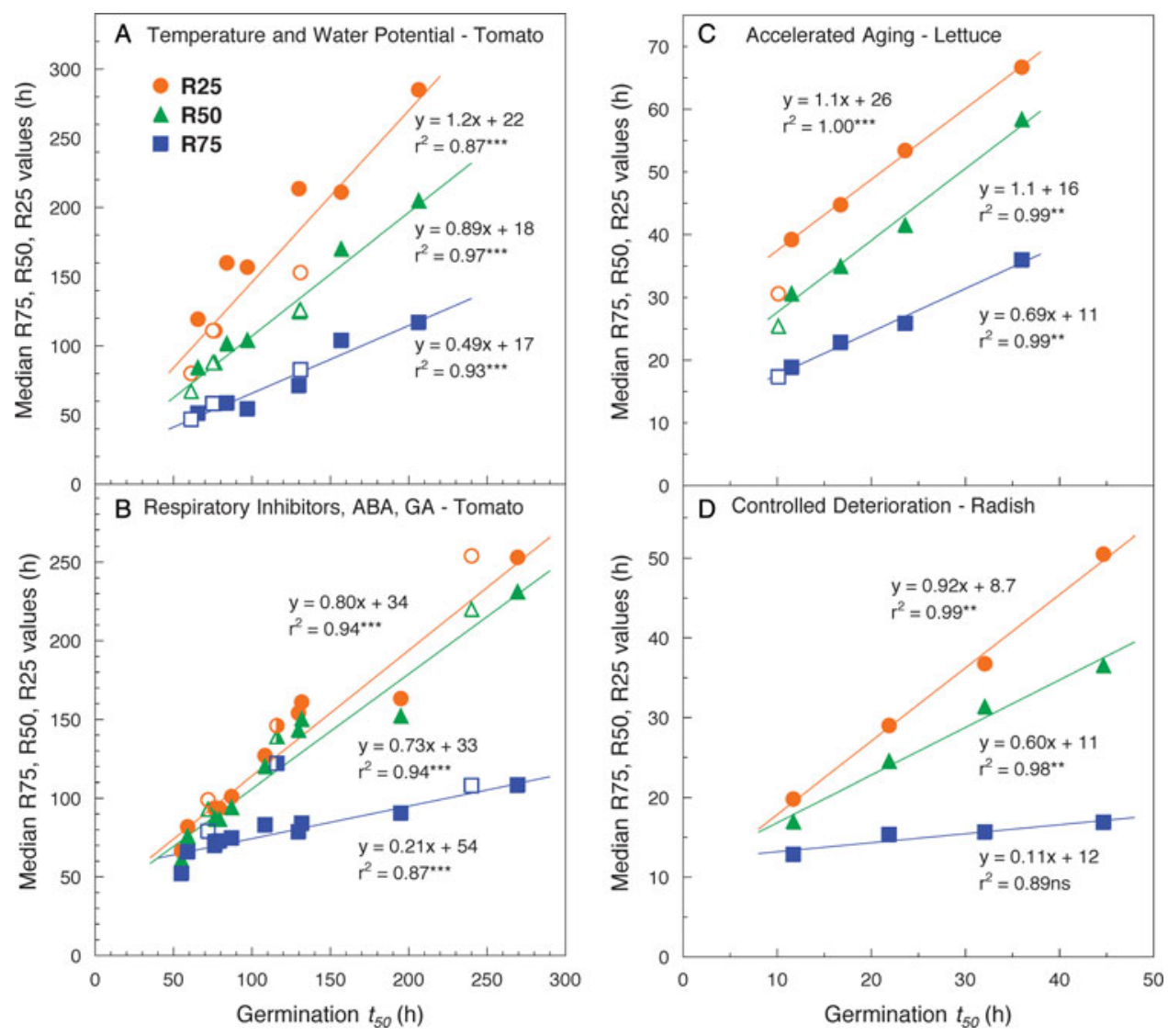

Figure 4. Relationships between median times to radicle emergence $\left(t_{50}\right)$ and the median times for seeds to reduce the oxygen in their wells to $75 \%$ (blue squares), $50 \%$ (green triangles) or 25\% (orange circles) of the initial value for: (A) tomato seeds imbibed at different temperatures (open symbols) or water potentials (closed symbols); (B) tomato seeds imbibed in different concentrations of KCN, SHAM or KCN + SHAM (closed symbols), of ABA (open symbols) or of GA (half-closed symbols) (ABA and GA data not included in linear regressions); (C) lettuce seeds subjected to accelerated ageing (open symbols represent primed seeds, not included in the linear regressions); and (D) radish seeds subjected to controlled deterioration. Significance levels of the regression values are indicated as: ns, non-significant; ${ }^{* *}, P<0.01 ;{ }^{* * *}, P<0.001$.

and low $\Psi$ ranges to be normalized into single curves for germination and for respiration at each oxygen depletion level (Fig. 5A-C). This normalization based on the model parameters accounts for the effect of $\Psi$ and adjusts each curve to what it would be expected to be in water, in a similar way that plotting on a thermal time scale normalizes time courses across temperatures (Bradford, 1990). As noted above, $T$ and $\Psi$ conditions that had similar effects on germination rates $\left(t_{50}\right)$ also had very similar effects on respiration (Fig. 4A). This was also apparent in the similar parameter values for germination and R50 POD time courses in the HTT model (supplementary Table S1). The model also revealed interesting comparisons of various conditions in their effects on respiration. For example, R50 time courses for conditions that differed by $5^{\circ} \mathrm{C}$ or $\sim-0.25$ to $-0.4 \mathrm{MPa}$ coincided almost exactly: POD curves at $-0.2 \mathrm{MPa}$ and $25^{\circ} \mathrm{C}$ coincided with those at $0 \mathrm{MPa}$ and $20^{\circ} \mathrm{C}$; curves for $-0.4 \mathrm{MPa}$ at $25^{\circ} \mathrm{C}$ coincided with those for $-0.25 \mathrm{MPa}$ at $20^{\circ} \mathrm{C}$; curves for $-0.4 \mathrm{MPa}$ at $20^{\circ} \mathrm{C}$ coincided with ones for $0 \mathrm{MPa}$ at $15^{\circ} \mathrm{C}$, etc. (supplementary Fig. S2). This indicates that, as far as seed respiration and germination rates are concerned, the influences of $T$ and $\Psi$ are essentially interchangeable and additive, consistent with prior work on seed priming that demonstrated interchangeable and additive effects of $T$ and $\Psi$ on physiological advancement toward radicle emergence (Bradford and Haigh, 1994).

\section{Abscisic acid and gibberellin (hormone model)}

A variation of the hydrotime model was developed to describe the effects of different concentrations of abscisic acid (ABA) or gibberellin (GA) on seed germination rates (Ni and Bradford, 1992, 1993). Because ABA is an inhibitor of germination, the analysis of ABA responses assumes that there is a base concentration or dosage $\left(\mathrm{ABA}_{\mathrm{b}}\right)$ that will just prevent germination of a specific fraction $g$ of the seed population, and that these $\mathrm{ABA}_{\mathrm{b}}(g)$ values are normally distributed among the seed population. When a logarithmic ABA concentration scale was used, as hormonal responses are generally logarithmic with concentration (Bradford and 


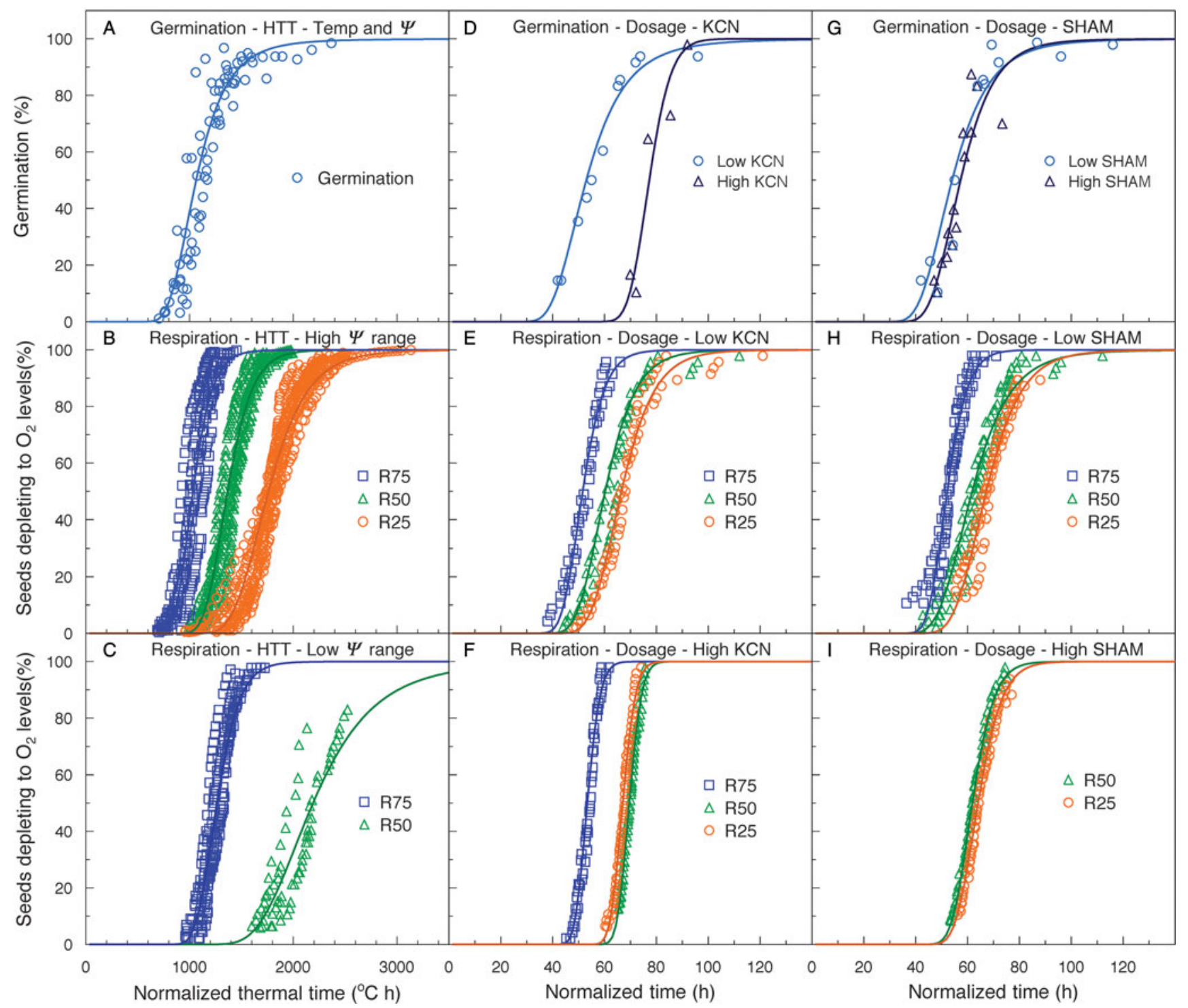

Figure 5. Normalized germination time courses (A, D, G) and POD time courses (B, C, E, F, H, I) for tomato seeds for R75 (blue squares), R50 (green triangles) and R25 (orange circles) oxygen depletion levels when imbibed at different temperatures and water potentials based upon the (HTT) model (A-C), or at different KCN or SHAM concentrations based on the dosage model (D-I) (see Fig. 3). Different data (symbols) and modelled responses (solid curves) are shown for higher and lower $\Psi$, KCN or SHAM concentrations (see Fig. 3 and text), except for germination at low water potentials (A), where no germination occurred. The normalization procedure for $\Psi$ or inhibitor dosage adjusts all time courses under different conditions back to their expected time courses in water (Bradford, 1990; Ni and Bradford, 1993).

Trewavas, 1994), times to germination were found to be inversely proportional to the difference between the $\mathrm{ABA}$ concentration applied in the test $[\mathrm{ABA}]$ and the $\mathrm{ABA}_{\mathrm{b}}(g)$ value for the specific fraction $g$. Based on that relationship, an ABA-time constant, $\theta_{\mathrm{ABA}}$ could be defined as:

$$
\begin{aligned}
\theta_{\mathrm{ABA}} & =\left\{\log [\mathrm{ABA}]-\log \left[\mathrm{ABA}_{\mathrm{b}}(g)\right]\right\} t_{g} \\
& =\left\{\log \left[\mathrm{ABA} / \mathrm{ABA}_{\mathrm{b}}(g)\right]\right\} t_{g}
\end{aligned}
$$

and the model parameters can be calculated as described previously according to:

$$
\log \left[\mathrm{ABA}_{\mathrm{b}}(g)\right]=\log [\mathrm{ABA}]-\theta_{\mathrm{ABA}} / t_{g} .
$$

An analogous model was developed for the promotion of germination by GA (Ni and Bradford, 1993), according to:

$$
\begin{aligned}
\theta_{\mathrm{GA}} & =\left\{\log [\mathrm{GA}]-\log \left[\mathrm{GA}_{\mathrm{b}}(g)\right]\right\} t_{g} \\
& =\left\{\log \left[\mathrm{GA} / \mathrm{GA}_{\mathrm{b}}(g)\right]\right\} t_{g} .
\end{aligned}
$$

To test the effects of $\mathrm{ABA}$ on seed respiration, we used seeds of the ABA-deficient sitiens $\left(\right.$ sit $\left.^{w}\right)$ tomato 
mutant, which germinate rapidly and are highly responsive to inhibition by ABA (Groot and Karssen, 1992; Ni and Bradford, 1993). Germination was delayed and reduced by imbibition in 1 and $3.3 \mu \mathrm{M}$ $\mathrm{ABA}$ and was almost completely inhibited by $10 \mu \mathrm{M}$ ABA (Fig. 6A). The median base ABA concentration required to inhibit germination by $50 \%$ according to the dosage PBT model was $4.8 \mu \mathrm{M}\left(\log \mathrm{ABA}_{\mathrm{b}}(50)=\right.$ 0.68) (Table 1). The PBT model fitted the respiration data well across ABA concentrations (see supplemental Fig. S3), showing a quantitative effect of increasing ABA concentration in decreasing seed respiration rates (Fig. 6B-D, Table 1). Initial rates of oxygen consumption (R75 POD curves) were reduced by ABA, but the concentration dependence was relatively small (Fig. 6B), while R50 and R25 POD curves more closely reflected the hormone concentration dependence for germination (Figs 6C, D). As discussed previously (Ni and Bradford, 1992), it is not possible to use a value of $0 \mathrm{ABA}$ concentration in a logarithmic model; instead, we estimated the minimum ABA concentrations that would be expected to have any effect on germination or respiration and used those values in the model to predict time courses in the absence of added ABA. For germination, this predicted minimum threshold value for an effect of ABA was $0.08 \mu \mathrm{M}$, compared to estimated values of $0.08 \mu \mathrm{M}$ for R50 and 0.10 $\mu \mathrm{M}$ for R25 POD curves. Interestingly, respiration rates at high ABA concentrations at which germination is inhibited declined continuously over time to very slow rates (see supplementary Fig. S4), suggesting that a feedback mechanism exists to reduce the respiration rates of seeds that will not complete germination due to low $\Psi$ (Fig. 2B) or high ABA (Fig. 6A), in order to conserve seed reserves.

This was also evident in the respiratory patterns of GA-deficient gib1 mutant tomato seeds, which are dependent upon exogenous GA to germinate (Groot and Karssen, 1987; Ni and Bradford, 1993). Respiration and germination increased in concert with GA concentration and were described well by the dosage PBT model (Fig. 6E-H; supplementary Fig. S3E-H). For both GA and ABA, there was a linear relationship between times to $50 \%$ germination (at concentrations where this percentage was attained) and median respiration rates derived from the POD curves (Fig. 4B). However, at lower GA concentrations that did not result in germination, initial oxygen consumption rates quickly declined to essentially zero (see supplementary Fig. S4F-H) and did not even reach R75 (Fig. 6F-H). This indicates that seeds that are not progressing toward germination (i.e. are dormant or lack other conditions permitting germination) can essentially stop oxidative respiration even though they are fully imbibed. The lack of oxygen consumption in these imbibed viable but dormant seeds also indicates that other reactions that could utilize oxygen [e.g. phenol oxidation or other chemical reactions; Lenoir et al. (1986)] must be negligible in these seeds.

\section{Germination and respiration responses to respiratory inhibitors (dosage model)}

Given the close relationships between oxygen consumption and germination rates, we asked whether directly inhibiting respiration rates would have corresponding effects on germination rates. We developed a model to account for changes in germination when respiration is artificially inhibited by addition of different concentrations (dosages) of KCN or SHAM:

$$
\operatorname{probit}(g)=\left\{\log (D)-\left(\theta_{D} / t_{g}\right)-\log \left[D_{\mathrm{b}}(50)\right]\right\} / \sigma_{D \mathrm{~b}}
$$

where $D$ is the tested dosage of KCN or SHAM, $\theta_{D}$ is the dosage time constant, $D_{\mathrm{b}}(50)$ is the median base dosage that reduces germination to $50 \%$, and the distribution of $D_{\mathrm{b}}(g)$ among seeds in the population is characterized by $\sigma_{D \mathrm{~b}}$, or the standard deviation of $D_{\mathrm{b}}(g)$. This is a general PBT model for effects of chemicals on germination rates and can be used in either logarithmic or linear mode, depending upon the seed responses to the dosage levels.

At high concentrations of $\mathrm{KCN}$, germination of lettuce ( $L$. sativa) seeds was reported to be completely inhibited (Khan and Zeng, 1985), and KCN-sensitive respiration accounted for about $80 \%$ of the total oxygen consumption in cocklebur (Xanthium strumarium) seeds (Esashi et al., 1981). However, in prior work with tomato seeds (Dahal et al., 1996), inhibiting or enhancing respiration rates by reducing or elevating oxygen concentrations had relatively little effect on the time of initiation of germination. In the Q2, increasing concentrations of $\mathrm{KCN}$ progressively delayed germination and reduced oxygen consumption rates of tomato seeds (Figs 3I and 2C, respectively). In general, seed oxygen consumption was much more sensitive to $\mathrm{KCN}$ than was final germination percentage, which was only reduced at higher $\mathrm{KCN}$ concentrations. The inhibitor delayed germination and increased the spread of radicle emergence, although $90 \%$ of seeds eventually completed germination. $\mathrm{KCN}$ affected primarily the duration (not the rate) of the initial phase of oxygen uptake before the transition to a more rapid rate (Fig. 2C), which coincided with radicle emergence. Times to $50 \%$ germination $\left(t_{50}\right)$ were highly correlated with median times for POD curves (Fig. 4B). As for $T$ and $\Psi$, germination and respiration time courses at a range of $\mathrm{KCN}$ concentrations can be modelled by the dosage-based PBT model (equation 7; Fig. 3I-L; Table 1). As the response was logarithmic, the minimum threshold for a response was estimated to be $0.05 \mathrm{mM} \mathrm{KCN}$, which was used for plotting the predicted curves for control seeds (Fig. 3I-L). 


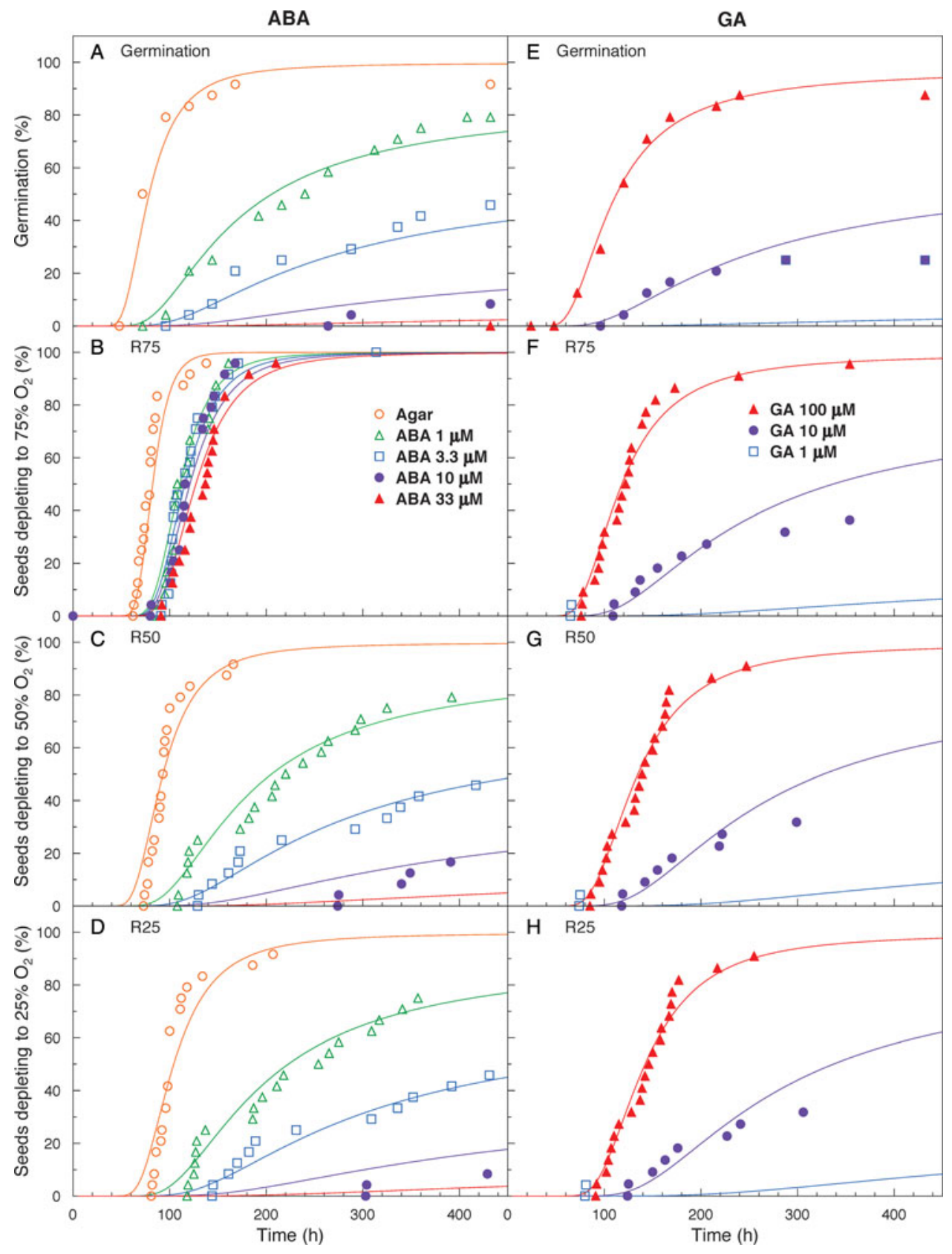

Figure 6. Germination time courses (A, E) and R75, R50 and R25 POD time courses (B-D, F-H) of ABA-deficient sit ${ }^{w}$ (A-D) and gibberellin-deficient gib1 (E-H) mutant tomato seeds imbibed on agar with different concentrations of ABA (A-D) or GA $(\mathrm{E}-\mathrm{H})$ at $25^{\circ} \mathrm{C}$. As no seeds reached the $75 \%$ oxygen depletion level at GA concentrations less than $10 \mu \mathrm{M}$, no data are shown, but the predicted time course for $1 \mu \mathrm{M}$ is plotted (see supplementary Fig. S4 for actual respiration time courses for these conditions).

Resembling the situation encountered with lower $\Psi$, seeds at higher KCN dosages adjusted their sensitivity thresholds and the populations became more uniform ( $\sigma$ decreased) (Table 1$)$, and therefore responded differently than would be predicted by the model based on their responses to lower concentrations (Fig. 3I-L). Separating the dosages of $\mathrm{KCN}$ into high and low categories enabled each model to fit the individual seed data for both germination and respiration with high precision (see supplementary Fig. S1I-L; Table 1), as shown by the ability to normalize the data from each concentration range to single time courses using the dosage model (Fig. 5D-F) (Ni and Bradford, 1993).

The inhibition of respiration and the eventual recovery of germination in the presence of KCN suggested that tomato seeds might be capable of respiration via the alternative metabolic pathway that is sensitive to the inhibitor SHAM (Esashi et al., 1981). As for KCN, oxygen consumption rates were reduced in a dosagedependent manner when tomato seeds were treated with SHAM (Fig. 2D), with a minimum response 
threshold estimated to be $0.4 \mathrm{mM}$ for germination or $0.1-0.2 \mathrm{mM}$ for respiration. This dosage dependence in response to SHAM was also complex, and showed two distinct response threshold regions, as occurred for KCN (Fig. 3M, O, P; Fig. 5G-I), except that increasing SHAM concentration above $2 \mathrm{mM}$ had no further effect on R75 (Fig. 2D). Thus, only a single model was applied to the R75 data from 0 to $2 \mathrm{mM}$ (Figs $3 \mathrm{~N}, 5 \mathrm{H})$. The differences in respiratory behaviour (R50 and R25) at low and high SHAM concentrations were accounted for by changes in all three parameters of the dosage model (Table 1). These sensitivity shifts could be due to metabolism of the inhibitors over time or shifts to alternative respiratory pathways. The different responses to inhibitor dosages provides evidence that metabolic adjustments can occur when respiration is inhibited, with possible relevance to the shift in $\Psi_{\mathrm{b}}(g)$ thresholds following incubation at low $\Psi$ (Fig. 3F, G).

Given the presence of both cyanide-sensitive and cyanide-insensitive respiratory pathways in tomato seeds, we also tested the effects of combined exposure to both KCN and SHAM. As might be expected, when both respiratory pathways were blocked, both oxygen consumption and germination were strongly inhibited (supplementary Table S1). When the relationships between $t_{50}$ for germination and median values for POD curves were plotted across all KCN and SHAM concentrations in which germination reached $50 \%$, all points for a given oxygen depletion level fell on a similar linear trend (Fig. 4B). Thus, regardless of which respiratory pathway was inhibited, a given reduction in oxygen consumption rates was associated with a corresponding delay in germination rates. These results further support the conclusion that respiration, rather than other oxygen-consuming reactions, is primarily responsible for the oxygen depletion measured in the Q2. Interestingly, the relationships between germination rates and respiration rates in response to $\mathrm{ABA}$ and GA were similar to those for KCN and SHAM (Fig. 4B).

\section{Germination and respiration responses to accelerated ageing and controlled deterioration (ageing model)}

One of the earliest indications of seed ageing and deterioration is a slowing of the rate of germination, well before total viability is affected (Dell'Aquila, 1987; Tarquis and Bradford, 1992). We therefore asked whether such delays were also evident in respiration rates as seeds age. A PBT model has been developed specifically to analyse the germination time courses of seeds during ageing (Bradford et al., 1993). This model estimates the predicted maximum longevity of seeds under the storage conditions tested based upon changes in germination rates over storage times. The model assumes that seeds in the population exhibit a distribution of maximum potential lifetimes under the storage conditions $\left(p_{\max }(g)\right)$, and that the delay in germination with increasing ageing period is proportional to the fraction of that potential maximum storage lifetime that has already passed for each seed. That is, as the accumulated ageing period $(p)$ approaches the maximum potential lifetime $\left(p_{\max }\right)$, the time to germination increases proportionately until germination does not occur at all (i.e. time to germination is infinite or germination rate is zero), which can be described as $\theta_{\text {age }}=\left[p-p_{\max }(g)\right] t_{g}$, where $\theta_{\text {age }}$ is the ageing time constant. The model can be fit as described previously (Bradford et al., 1993):

$$
\operatorname{probit}(g)=\left[p-\left(\theta_{\text {age }} / t_{g}\right)-p_{\max }(50)\right] / \sigma_{p} \max
$$

where $p_{\max }(50)$ is determined from the midpoint of the regression line and refers to the ageing period at which germination is reduced to $50 \%$ and $\sigma_{p \max }$ is the standard deviation of $p_{\max }$ values among seeds in the population. We call this the 'metronome model' of seed ageing, as it implies that each seed has a maximum potential number of 'ticks' before losing viability $\left(p_{\max }\right)$, and the storage conditions (primarily moisture content and temperature) speed up or slow down the rate (in standard clock time) at which these ticks are used up, just as a metronome can run faster or slower depending upon the musical tempo.

Two types of rapid ageing treatments were tested: (1) controlled deterioration (33\% RH equilibration followed by incubation at $50^{\circ} \mathrm{C}$ ) for radish ( $R$. sativus) seeds; and (2) more severe accelerated ageing (75\% $\mathrm{RH}$ equilibration followed by incubation at $50^{\circ} \mathrm{C}$ ) for lettuce seeds. We evaluated the effects of ageing on respiration and germination simultaneously by observing the radicle emergence times of individual seeds in the vials during Q2 measurements, so that individual oxygen depletion curves could be colour-coded based on the times of completion of germination of that same seed (see supplementary Fig. S5). In both cases, ageing conditions and time periods were selected that affected germination rates but viability remained high (Fig. 7A, E). The effects of both types of ageing conditions were readily apparent in delayed germination and slower oxygen depletion rates following imbibition (Fig. 7; supplementary Fig. S5). The PBT ageing model fitted well to both germination and respiration (i.e. POD curve) data for both species and ageing conditions (Table 1), as can be seen from comparison of the predicted and actual values (Fig. 7A-H, solid lines and symbols, respectively) and from the regression plots used to fit the models using equation (8) (see supplementary Fig. S6). This is also evident in the linear correlations between $t_{50}$ values for germination and median times of the POD 


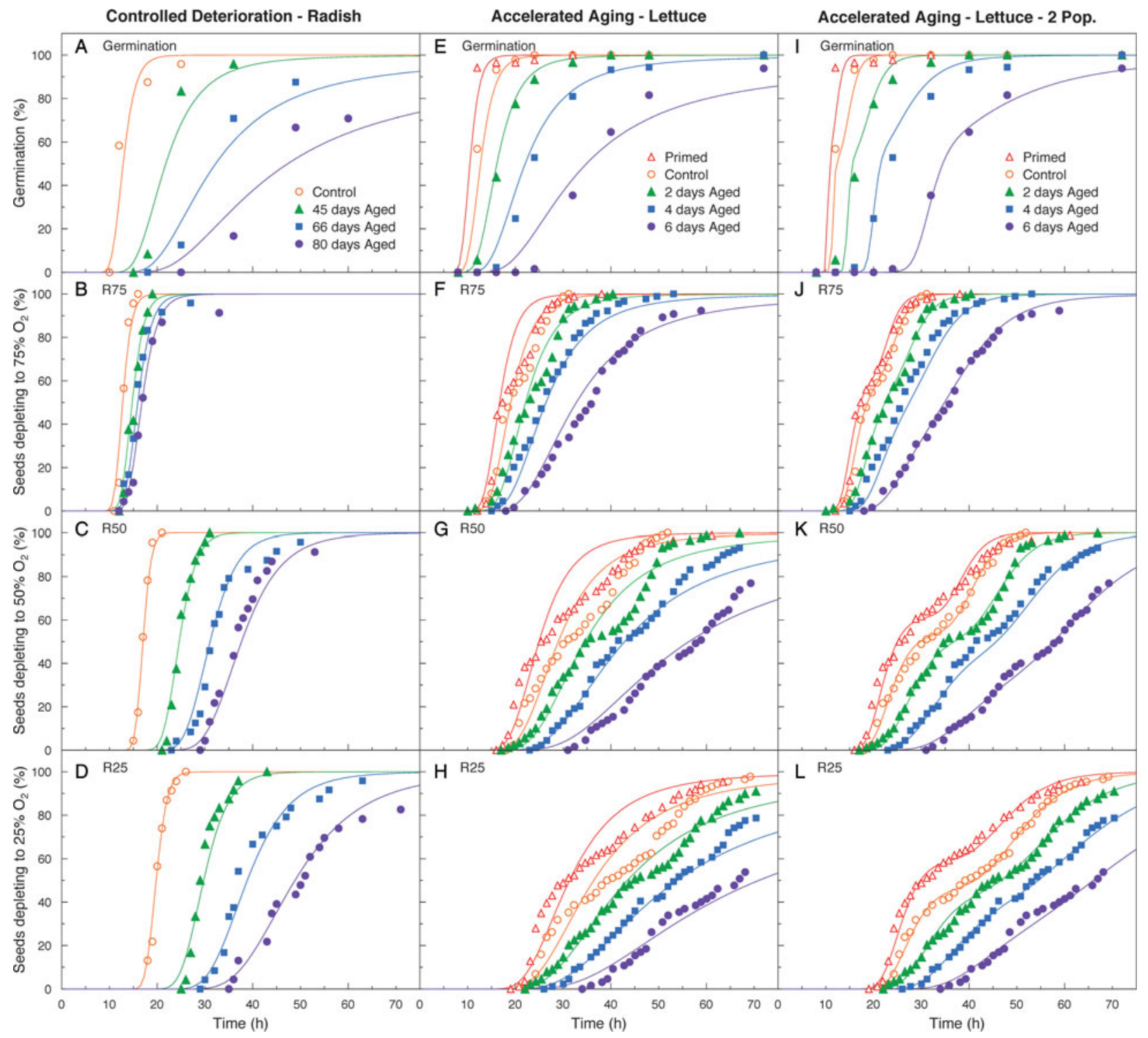

Figure 7. Germination time courses (A) and R75, R50 and R25 POD time courses (B-D) for untreated (control) radish seeds (open orange circles) or after 45 (green triangles), 66 (blue boxes) or 80 (dark blue circles) days of controlled deterioration at $33 \%$ $\mathrm{RH}$ and $50^{\circ} \mathrm{C}$. Similarly, germination time courses (E and I) and R75, R50 and R25 POD time courses (F-H and J-L) for untreated (control) lettuce seeds (open orange circles), primed seeds (open red triangles) or seeds after 2 (green triangles), 4 (blue boxes) or 6 (purple circles) days of controlled deterioration at $75 \% \mathrm{RH}$ and $50^{\circ} \mathrm{C}$. The time courses predicted by the ageing time model for germination or respiration data are represented for all treatments on panels $\mathrm{A}-\mathrm{H}$ as solid lines of the corresponding colour. Primed seeds were modelled using -1 day of 'ageing' time. Additionally, solid lines in panels I-L illustrate predicted time courses based upon summing the contributions of two distinct subpopulations in the seed lot (for details see supplementary Fig. S7).

curves (Fig. 4C, D). The lack of a significant slope at the higher oxygen threshold level (R75) for radish seeds is due to the relatively small effect of ageing on the initial respiration rate of radish seeds compared to the delays in transition to higher respiration rates (supplementary Fig. S5A-D). In contrast to radish, respiratory patterns for individual lettuce seeds were quite heterogeneous within the population (supplementary Fig. S5E-H). Due to the presence of both sigmoid and linear respiratory patterns, average curves across the seed population resulted in patterns that did not match those of any individual seed (supplementary Fig. S5E-H, dashed black lines). Median curves somewhat more closely matched the actual shapes of the individual seed patterns, but again were a compromise among the different respiratory patterns exhibited (supplementary Fig. S5E-H, solid black lines). Germination of most control seeds was completed within $16 \mathrm{~h}$, well before the large differences in subsequent respiration patterns occurred, which apparently reflect variation in respiration rates of lettuce seedlings. Q2 data for individual lettuce 
seeds/seedlings illustrate the wide physiological variation that can exist within apparently uniform seed lots (Still and Bradford, 1997).

Although the PBT model matched the overall respiratory pattern of ageing lettuce seeds relatively well (Fig. 7F-H), the double-sigmoid shape of the POD curves suggested that the seed lot was composed of two subfractions with different respiratory behaviours (particularly evident in Fig. 7G). The presence of subpopulations in the lettuce seed lot is also evident from the 'bend' (non-linearity) in the probit regressions of the lettuce ageing data, as compared to the linear probit plots (normal distribution) for the radish data (see supplementary Fig. S6F-H). We further analysed the lettuce data by assuming that the seed lot contained two different subpopulations with distinct respiratory threshold distribution parameters and responses to ageing. We then modelled the complete population time courses by summing the predicted time courses of each subpopulation across the time course (supplementary Fig. S7B-D; supplementary Table S2; modelling approach described in supplementary Fig. S7). This greatly improved the match between the modelled and actual respiratory behaviour of the complete population (Fig. 7J-L; supplementary Fig. S7J-L). We note that while subpopulations are quite obvious in the POD curves, the lower frequency of sampling for germination time-course data would not in itself justify a two-population model (Fig. 7E). However, applying the same approach to the germination data also improved the match of the model to the data across ageing periods (Fig. 7I; supplementary Fig. S7A, I). This modelling approach could theoretically be extended to include as many subpopulations as are justified by the data. In this way, complex germination or POD time courses can be 'deconvoluted' into multiple subpopulations, each with its own distribution and response to environmental, hormonal or chemical factors.

\section{Germination and respiration responses to seed priming (ageing model)}

Seed priming is a technique for accelerating germination by prehydrating seeds under controlled conditions to initiate germinative metabolism but prevent radicle emergence, which is then followed by seed drying (Bewley et al., 2013). When primed seeds are subsequently imbibed, they exhibit accelerated germination rates. We therefore asked whether primed seeds also exhibit correspondingly accelerated respiration rates during imbibition. The same lettuce seed lot that was used for the ageing study was also primed and assayed for germination and respiration rates. Times to germination of lettuce seeds were slightly shortened by priming compared to control (untreated) seeds (Fig. 7E, I; supplementary Fig. S5E, I), but initial respiration rates were relatively unaffected, with the exception that slower germinating seeds now exhibited more rapid rates of oxygen depletion and shifted to more sigmoid patterns (supplementary Fig. S5I). This was also evident as a greater effect of priming on median R25 values than on R75 or R50 values (Fig. 4C, open symbols). Germination and respiration time courses of primed lettuce seeds were modelled using the same ageing model parameters developed for the accelerated ageing data, but using a 'negative ageing' time of $-1 \mathrm{~d}$ under those ageing conditions and slightly adjusting the fraction of seeds in each subpopulation (see legend of supplementary Fig. S7). Priming may not actually 'negatively age' or 'rejuvenate' seeds, but its effect in advancing germination and accelerating respiration was equivalent to a negative ageing time in this model (Fig. 7E-H), and this worked particularly well when the subpopulation model was applied (Fig. 7I-L).

\section{Discussion}

\section{Practical applications of single-seed respiration measurements}

The development of sensitive optical oxygen-sensing technology (Draaijer et al., 1999) and its application to seed biology via the Q2 instrument (Van Duijn and Konig, 2001; Van Asbrouck and Taridno, 2009; www. astec-global.com) enables the measurement of detailed oxygen consumption time courses for individual seeds. These highly precise data provide insight into the relationship between respiration and germination in seed populations. Previous approaches to the analysis of Q2 data, utilizing the software provided with the instrument, focused on: (1) fitting equations to the original oxygen depletion time courses; (2) deriving parameters from the shape and timing of features in those time courses; and (3) averaging those values across the seed population (Van Asbrouck and Taridno, 2009; Zhao and Zhong, 2012; Bradford et al., 2013; Zhao et al., 2013). Although the information provided by this analysis was useful to compare the vigour of seed lots, this approach had some limitations. First, the analyst had to inspect the data for each seed and assure that it was properly fit by the software's equation. The analyst often had to adjust the parameters manually to achieve acceptable fits, making the data analysis process inefficient and time consuming. Second, in many cases when different conditions were applied, the oxygen depletion curves no longer had the expected shape (e.g. Fig. 2B), which resulted in loss of data for those parameters that relied on a particular component of those curves. To resolve this problem, some researchers simply removed data for those seeds from their analyses 
(Zhao et al., 2013), but this strongly biases the results by restricting the analysed dataset to a variable subfraction of the total seed population. In the case of lettuce seeds, which generally exhibit a range of oxygen depletion patterns (supplementary Fig. S5), this approach would consistently censor data for a significant fraction of the seed population. Thus, while recognizing the potential for the Q2 to acquire precise single-seed data robotically and at frequent time intervals, we sought alternative approaches to analyse the resulting data.

After trying various approaches, we developed a method that ignores the shapes of the oxygen depletion curves and instead plots the cumulative percentage of seeds that had achieved specific levels of oxygen depletion at increasing times after imbibition. The resulting 'population oxygen depletion' (POD) curves provide immediate visual information related to seed respiratory performance, directly analogous to seed germination time courses. More importantly, these POD curves can be analysed using the same models that have been applied to germination time-course data. In fact, the models generally fit better to the POD curves than to germination time courses, as respiratory information is available for every seed at frequent time intervals, in contrast to the more sparse germination data that are generally snapshots of germination progress at selected time points, and vary in density according to the speed of germination and the observation frequency. Having fit the appropriate PBT models to the full dataset (e.g. Fig. 3), unbiased median values can be derived (e.g. Fig. 4) as well as measures of the population variances ( $\sigma$ values). While there has been considerable discussion in the seed literature about a need for alternative statistical methods and use of nonnormal distributions for applying PBT models to germination data (Bloomberg et al., 2009; Watt et al., 2011; Hay et al., 2014; Hardegree et al., 2015), the majority of our results with POD curve data fit the assumptions of the normal distribution and probit analysis extremely well (Table 1; supplementary Figs S1, S3, S6). In addition, the richness of the raw POD data clearly indicates when physiological parameters have changed in the seed population, such as at low $\Psi$ or high inhibitor concentrations (Figs 3, 5; supplementary Fig. S1).

In cases where a single normal distribution of seed response thresholds does not describe the data as well as expected (e.g. Fig. 7F-H), it is likely to be due to the existence of subpopulations of seeds within the seed lot having distinct germination and respiration characteristics. Such subpopulation structure within a seed lot may not be evident in the more sparse germination data (Fig. 7E), demonstrating the value of having data for each individual seed in a population. Using the higher-resolution POD data, we have extended our analyses to show that seed lots can be partitioned into separate subpopulations by applying multiple
PBT models to the same dataset (supplementary Fig. S7). In this case, direct multivariate fitting of the data and minimizing the residual error was used, rather than probit analysis, to define the parameters of the two subpopulations (see the legend to supplementary Fig. S7). Summing the predicted time courses for the two (or more) overlapping subpopulations reproduces the complete complex time course of the total seed population, in a biological analogy to deconvoluting a complex absorbance spectrum into the sum of subspectra using Fourier transform methods (Stein and Shakarchi, 2003). We believe that this is a more biologically relevant approach to analysing complex germination patterns of specific seed lots, rather than seeking to fit a specific mathematical distribution empirically to describe the entire population (e.g. Watt et al., 2011). Only two normally distributed subpopulations can reproduce a wide range of non-normal distributions in the total population, depending upon their means and standard deviations relative to each other (e.g. supplementary Fig. S7E-H), and additional subpopulations can be added, if needed, to fully account for the characteristics of the seed lot. It is a biological and commercial fact that many seed lots are mixtures of multiple subpopulations, whether it is due to different genotypes, locations of seeds in the fruit or on the mother plant, maturity dates, dormancy mechanisms or purposeful blending of commercial seed lots (Roach and Wulff, 1987; Egli, 1998; Bewley et al., 2013). Regardless of the source, variations in the performance of seed lots ultimately trace back to the characteristics of the individual seeds present in the populations, so methods that reveal, quantify and characterize those subpopulations will ultimately be more useful (e.g. for cleaning and conditioning seed lots as well as for understanding natural variation) than fitting an arbitrary overall population distribution on to each unique seed population. This may be particularly useful for non-cultivated species, where seed lots collected in the wild could be expected to contain multiple subcomponents (e.g. Bloomberg et al., 2009; Finch-Savage and Bassel, 2016). An exception to this could be where the primary interest is in the average population behaviour in an ecological context, as, for example, in modelling the seasonal timing of maximum weed emergence, where greater precision may be superfluous, or subpopulations may be multiple and undefined (Forcella et al., 2000; Grundy, 2003; Meyer and Allen, 2009; Boddy et al., 2012).

Our results indicate that with respect to many conditions influencing seed germination, POD curves can substitute for germination time courses. As germination rates are among the most sensitive indicators of seed vigour or its loss (Matthews and Powell, 2011), this should enable the use of respiration rates for vigour ratings of seed lots. A particularly attractive application would be to indicate the potential longevity of 
seed lots for germplasm conservation. Seed populations generally exhibit an extended period of high viability in storage, followed by a relatively rapid loss of viability (Walters, 1998). The length of the initial period of high viability varies among seed lots and is largely unpredictable, resulting in frequent testing, using up stored seed samples and resulting in the need for expensive regeneration, even if sample viability still remained high (Walters et al., 2005). Multiple lines of research are being pursued to better understand the mechanisms of seed ageing, to identify molecular and biochemical markers that could assist in the prediction of viability loss over storage time, but to date these have not resulted in practical tools to anticipate potential seed longevity (Fu et al., 2015). However, periodic Q2 tests of seed lots during an initial period of their storage under constant temperature and moisture conditions would reveal shifts in POD curves that can be used in the PBT ageing model to predict when viability would fall to a prescribed percentage. While requiring experimental verification, this would be an efficient empirical method to estimate the potential length of the initial plateau storage period for specific seed lots, and to enable adjustment of testing schedules and storage conditions accordingly.

\section{Implications of respiration-germination relationships}

As reported here, a close relationship exists between the effects on seed respiration and germination of $T$, $\Psi$, their combination, ABA, GA, respiratory inhibitors, ageing and priming. Such broad parallel behaviour across all of these conditions suggests the possibilities that all of these factors act on germination through their effects on respiration or that sensitive feedback relationships operate to adjust metabolic rates to developmental progress. Following imbibition and during germination, ATP production in the mitochondria is the primary source of metabolic energy in seeds (Hourmant and Pradet, 1981; Al-Ani et al., 1985) generated through oxidative phosphorylation (Frey and Mannella, 2000; Logan et al., 2001). Progress toward germination relies on respiration, as shown here by the effects of the respiratory inhibitors $\mathrm{KCN}$ and SHAM. Either inhibitor alone reduced respiration rates, but germination was capable of recovering. However, in the presence of both inhibitors, blocking both the cytochrome $c$ and the alternative respiratory pathways, respiration rates were low and germination was prevented (supplementary Table S1). The effects on germination rates of limiting oxygen availability, which would also reduce respiration rates, are also consistent with PBT models (Bradford et al., 2007). This implies that a quantity of 'respiration-time' (in analogy to thermal time) must be accomplished or accumulated by a seed before radicle emergence can be completed. Part of this presumably supports repair activities, as seed ageing initially slows germination rates before viability is lost, but normal seedlings resulting from aged but viable seeds can grow at the same rates as seedlings from unaged seeds after germination occurs, indicating that they have not sustained permanent damage (Tarquis and Bradford, 1992; Baker, 1995). Thus, ageing may initially affect principally respiratory capacity, and slower rates of respiration take longer to accomplish the metabolic events required to prepare for radicle emergence. Mitochondria have been proposed to be the primary targets for ageing damage during accelerated ageing (Amable and Obendorf, 1986; Ferguson et al., 1990; Fu et al., 2015), possibly as a result of the action of free radicals and reactive oxygen species (McDonald, 1999; El-Maarouf-Bouteau and Bailly, 2008). Furthermore, the oxidative properties of purified pea seed mitochondria improved during imbibition and due to priming, indicating a correlation between seed quality and mitochondrial function (Benamar et al., 2003). Consistent with this, mitochondrial membrane structure was damaged, the matrix became less dense and mitochondrial biogenesis during seed imbibition was inhibited in aged soybean seeds compared to control seeds (Xin et al., 2014). Thus, it is not surprising that there are close relationships between respiration rates and germination rates in response to inhibitors, oxygen and ageing.

While consistent effects of temperature on respiration and germination rates would be intuitive due to the underlying thermodynamics, the basis for the similar effects of $\Psi$ is less clear. $T$ and $\Psi$ have closely equivalent effects on respiration rates of tomato seeds for a given change in germination rates (Fig. 4A; Dahal et al., 1996). Similarities in $T$ and $\Psi$ effects on germination have been implied in the parallel structure of the thermal time and hydrotime models, and in the assumptions of the hydrothermal time model (Gummerson, 1986; Bradford, 1990; Bradford and Haigh, 1994; Alvarado and Bradford, 2002). However, although water stress is known to inhibit respiration in other plant tissues, this generally occurs only at lower $\Psi$ and is less sensitive to $\Psi$ than is photosynthesis, for example (Ribas-Carbo et al., 2005). Preliminary measurements of the respiration of leaf discs incubated at different $\Psi$ in the Q2 found little effect on respiration rates at the relatively high $\Psi$ levels at which seed respiration rates are significantly affected (our data, not shown; B. Vandenbussche and SESvanderHave, pers. comm.). Thus, seeds appear to have an especially sensitive response to $\Psi$ with respect to both respiration and germination. Earlier analyses of the water relations of germination suggested that effects on cellular turgor and associated expansion might transduce effects of $\Psi$ into metabolic consequences (Bradford, 1986), as also proposed recently on the basis of molecular data (Dekkers et al., 2013; Nonogaki, 2014). However, 
other data and arguments point to metabolic processes, such as transcriptional changes and enzymatic endosperm weakening, to control the timing of radicle emergence (Nonogaki et al., 2007; Weitbrecht et al., 2011). Regardless, seed respiration is particularly sensitive to $\Psi$ and responds quantitatively to different stress levels, as shown by the close fit of the hydrotime model to respiration data (Fig. 3).

Seed progress toward germination is closely attuned to $\Psi$ and makes adjustments in response to incubation at low $\Psi$ (Dahal and Bradford, 1994), which we show here to occur also for respiration in response to both $\Psi$ and respiratory inhibitors (Fig. 3). Water availability is critical for germination and for the success of the resulting seedling, and germination is even more sensitive to reduced $\Psi$ than is seedling growth (Ross and Hegarty, 1979). Thus, the high sensitivity of seed respiration to reduced $\Psi$ could serve to delay or prevent completion of germination to enable the seed to make the determination of whether the conditions are adequate for subsequent seedling growth (Finch-Savage and Bassel, 2016). The phenomenon of seed priming demonstrates that physiological progress toward germination can occur at $\Psi$ levels below those permitting radicle emergence (Bradford and Haigh, 1994), but further reducing seed water contents slightly below those levels stops progress toward germination and initiates processes associated with desiccation tolerance and seed longevity (Bruggink et al., 1999). Seeds carry finite amounts of reserves, so reducing metabolic rates when $\Psi$ is sensed as being too low to support germination, or as a harbinger of future desiccation, would make evolutionary sense in terms of seed survival. It is unknown how such changes in $\Psi$ are perceived in the seed, and whether the initial response is to reduce respiration rates or metabolism slows as a secondary response to delayed developmental progress (Dahal et al., 1996). Seeds lacking GA, or exposed to high concentrations of ABA that will prevent germination, also rapidly reduce their respiration rates to very low levels following imbibition (supplementary Fig. S4). Dormant rice seeds also exhibited low but constant rates of respiration (Footitt and Cohn, 1995), and extreme reductions in respiration rates were observed in the embryos of some fish species during diapause (animal dormancy) (Podrabsky and Hand, 2015). Thus, seeds appear to have feedback mechanisms that reduce respiration rates when the probability of successful completion of germination and subsequent seedling growth is low due to environmental conditions or dormancy.

\section{Broader applications of the technology}

In addition to seeds, the oxygen consumption of any biological material that can fit into a microtitre plate (from 24- to 96-well) or a screw-cap vial could be measured using the existing Q2 instrument. The gas volume in the wells can be easily adjusted by varying the amount of agar (or other substrate) used, thereby increasing or decreasing the sensitivity for different amounts of tissue or respiration rates. Furthermore, when oxygen levels in the Q2 vials are low and green seedlings are present, as at the end of a standard germination measurement, the production of oxygen due to photosynthesis can be detected. It is feasible, therefore, that the instrument could also be adapted to measure processes that generate oxygen as well as consume it. Thus, the instrument itself could be utilized more broadly for measuring respiration or oxygen production of diverse tissues, to enable individual measurements and greater replication. For example, Clark-type electrodes (Edelstein and Welbaum, 2011) and microcalorimetry (Criddle and Hansen, 1998; Edelstein et al., 2001) have also been used to measure respiratory rates of seeds and other plant tissues. However, the limited number of sample chambers generally available with such equipment makes it time consuming to collect sufficient samples to estimate population parameters. The Q2 technology enables sensitive measurements of oxygen consumption, requires small amounts of tissue (i.e. individual Arabidopsis seeds have been measured) and enables simultaneous and robotic data collection from populations of individual samples.

Population-based threshold models have been highly successful in describing, quantifying and understanding the dynamics of botanical behaviours that are based on the independent developmental responses of individuals, whether plants, seeds or cells, to internal or external signals (Bradford, 1995; Donohue et al., 2015; Huang et al., 2015). In its original formulations, PBT models were focused on quantal or 'digital' phenomena (i.e. all or none responses such as germination) that must be analysed as populations of individuals (Rodbard, 1973; Bradford and Trewavas, 1994). The current work extends the applications of PBT models to respiratory metabolism itself, showing that individual seeds vary in their threshold respiratory rates and in the responses of respiration to diverse environmental and chemical inputs. This suggests that the underlying threshold relationship, i.e. that individual rates of metabolism and of developmental progress are proportional to the extent by which a given regulatory factor exceeds individual base sensitivity levels, applies to what have previously been thought to be quantitative rather than quantal responses. The combination of this simple threshold response mechanism with its expression cumulatively across populations of individuals that vary in the values of their response thresholds appears to be a fundamental organizing principle of the biology of multicellular organisms, and even of subcellular molecular interactions 
(Bradford and Trewavas, 1994; Trewavas, 2012, 2014; Bassel et al., 2014; Angel et al., 2015; Bintu et al., 2016). As technologies for detecting and measuring the metabolic and developmental behaviour of individuals at all levels of biological organization improve, further applications of PBT-based analytical approaches will provide revealing insights.

\section{Supplementary material}

To view supplementary material for this article, please visit http://dx.doi.org/10.1017/S0960258516000179

\section{Acknowledgements}

We thank our colleagues J.-C. Fu, M. Barros, Irfan Afzal, Keshavulu Kunusoth and Luís Eduardo Panozzo, who contributed to some of the original data presented here.

\section{Financial support}

This work was supported in part by the members of the Q2 Users Group (Bejo Zaden, Callas International, Coating Supply Inc., Enza Zaden, Germain's Technology Group, Hoopman Equipment, Incotec, Monsanto, Nickerson-Zwaan, Rhino Research, Rijk Zwaan, SESvanderHave and Syngenta), the American Seed Trade Association Vegetable and Flower Seed Permanent Research Fund, ASTEC Global (in-kind technical support), the Western Regional Seed Physiology Research Group and United States Department of Agriculture-National Institute of Food and Agriculture Regional Research Project W3168.

\section{Conflicts of interest}

None.

\section{References}

Al-Ani, A., Bruzau, F., Raymond, P., Saint-Ges, V., Leblanc, J.M. and Pradet, A. (1985) Germination, respiration, and adenylate energy charge of seeds at various oxygen partial pressures. Plant Physiology 79, 885-890.

Alvarado, V. and Bradford, K.J. (2002) A hydrothermal time model explains the cardinal temperatures for seed germination. Plant, Cell $\mathcal{E}$ Environment 25, 1061-1069.

Amable, R.A. and Obendorf, R.L. (1986) Soybean seed respiration during simulated preharvest deterioration. Journal of Experimental Botany 37, 1364-1375.

Angel, A., Song, J., Yang, H., Questa, J.I., Dean, C. and Howard, M. (2015) Vernalizing cold is registered digitally at FLC. Proceedings of the National Academy of Sciences, USA 112, 4146-4151.

Baker, E.H. (1995) The Maillard reaction, desiccation-related proteins, and nuclear replication stages: relationships to seed deterioration. PhD Dissertation, University of California, Davis.

Bassel, G.W., Stamm, P., Mosca, G., Barbier de Reuille, P., Gibbs, D.J., Winter, R., Janka, A., Holdsworth, M.J. and Smith, R.S. (2014) Mechanical constraints imposed by $3 \mathrm{D}$ cellular geometry and arrangement modulate growth patterns in the Arabidopsis embryo. Proceedings of the National Academy of Sciences, USA 111, 8685-8690.

Batlla, D. and Benech-Arnold, R.L. (2015) A framework for the interpretation of temperature effects on dormancy and germination in seed populations showing dormancy. Seed Science Research 25, 147-158.

Benamar, A., Tallon, C. and Macherel, D. (2003) Membrane integrity and oxidative properties of mitochondria isolated from imbibing pea seeds after priming or accelerated ageing. Seed Science Research 13, 35-45.

Bewley, J.D., Bradford, K.J., Hilhorst, H.W.M. and Nonogaki, H. (2013) Seeds: Physiology of development, germination and dormancy (3rd edition). New York, Springer.

Bierhuizen, J.F. and Wagenvoort, W.A. (1974) Some aspects of seed germination in vegetables. $I$. The determination and application of heat sums and minimum temperature for germination. Scientia Horticulturae 2, 213-219.

Bintu, L., Yong, J., Antebi, Y.E., McCue, K., Kazuki, Y., Uno, N., Oshimura, M. and Elowitz, M.B. (2016) Dynamics of epigenetic regulation at the single-cell level. Science 351, 720-724.

Bloomberg, M., Sedcole, J.R., Mason, E.G. and Buchan, G. (2009) Hydrothermal time germination models for radiata pine (Pinus radiata D. Don). Seed Science Research 19, 171-182.

Boddy, L.G., Bradford, K.J. and Fischer, A.J. (2012) Population-based threshold models describe weed germination and emergence patterns across varying temperature, moisture and oxygen conditions. Journal of Applied Ecology 49, 1225-1236.

Bradford, K.J. (1986) Manipulation of seed water relations via osmotic priming to improve germination under stress conditions. Hortscience 21, 1105-1112.

Bradford, K.J. (1990) A water relations analysis of seedgermination rates. Plant Physiology 94, 840-849.

Bradford, K.J. (1995) Water relations in seed germination. pp 351-396 in Kigel, J.; Galili, G. (Eds) Seed development and germination. New York, Marcel Dekker Inc.

Bradford, K.J. (2002) Applications of hydrothermal time to quantifying and modeling seed germination and dormancy. Weed Science 50, 248-260.

Bradford, K.J. and Haigh, A.M. (1994) Relationship between accumulated hydrothermal time during seed priming and subsequent seed germination rates. Seed Science Research 4, 1-10.

Bradford, K.J. and Still, D.W. (2004) Applications of hydrotime analysis in seed testing. Seed Technology 26, 75-85.

Bradford, K.J. and Trewavas, A.J. (1994) Sensitivity thresholds and variable time scales in plant hormone action. Plant Physiology 105, 1029-1036.

Bradford, K.J., Tarquis, A.M. and Duran, J.M. (1993) A population-based threshold-model describing the relationship between germination rates and seed deterioration. Journal of Experimental Botany 44, 1225-1234.

Bradford, K.J., Côme, D. and Corbineau, F. (2007) Quantifying the oxygen sensitivity of seed germination 
using a population-based threshold model. Seed Science Research 17, 33-43.

Bradford, K.J., Bello, P., Fu, J.C. and Barros, M. (2013) Single-seed respiration: a new method to assess seed quality. Seed Science \& Technology 41, 420-438.

Bruggink, G.T., Ooms, J.J.J. and van der Toorn, P. (1999) Induction of longevity in primed seeds. Seed Science Research 9, 49-53.

Buckley, W.T. and Huang, J. (2011) An ethanol-based seed vigour assay for canola. Seed Science \& Technology 39, 510-526.

Chantre, G.R., Batlla, D., Sabbatini, M.R. and Orioli, G. (2009) Germination parameterization and development of an after-ripening thermal-time model for primary dormancy release of Lithospermum arvense seeds. Annals of Botany 103, 1291-1301.

Covell, S., Ellis, R.H., Roberts, E.H. and Summerfield, R.J. (1986) The influence of temperature on seed-germination rate in grain legumes. 1. A comparison of chickpea, lentil, soybean and cowpea at constant temperatures. Journal of Experimental Botany 37, 705-715.

Criddle, R.S. and Hansen, L.D. (1998) Calorimetric methods for analysis of plant metabolism. pp. 711-763 in Kemp, R. B. (Ed.) Handbook of thermal analysis and calorimetry. Amsterdam, Elsevier.

Dahal, P. and Bradford, K.J. (1994) Hydrothermal time analysis of tomato seed germination at suboptimal temperature and reduced water potential. Seed Science Research 4, 71-80.

Dahal, P., Bradford, K.J. and Jones, R.A. (1990) Effects of priming and endosperm integrity on seed-germination rates of tomato genotypes. 1. Germination at suboptimal temperature. Journal of Experimental Botany 41, 1431-1439.

Dahal, P., Kim, N.S. and Bradford, K.J. (1996) Respiration and germination rates of tomato seeds at suboptimal temperatures and reduced water potentials. Journal of Experimental Botany 47, 941-947.

Dekkers, B.J.W., Pearce, S., van Bolderen-Veldkamp, R.P., Marshall, A., Widera, P., Gilbert, J., Drost, H.-G., Bassel, G.W., Müller, K., King, J.R., Wood, A.T.A., Grosse, I., Quint, M., Krasnogor, N., Leubner-Metzger, G., Holdsworth, M.J. and Bentsink, L. (2013) Transcriptional dynamics of two seed compartments with opposing roles in Arabidopsis seed germination. Plant Physiology 163, 205-215.

Dell'Aquila, A. (1987) Mean germination time as a monitor of the seed aging. Plant Physiology and Biochemistry 25, $761-768$.

Donohue, K., Burghardt, L.T., Runcie, D., Bradford, K.J. and Schmitt, J. (2015) Applying developmental threshold models to evolutionary ecology. Trends in Ecology $\mathcal{E}$ Evolution 30, 66-77.

Draaijer, A., Jetten, J. and Douma, A.C. (1999) A novel optical method to determine oxygen in beer bottles. Journal of the Institute of Brewing 105, 155.

Edelstein, M. and Welbaum, G.E. (2011) Seed $\mathrm{O}_{2}$ uptake and germination of cold-tolerant and cold-intolerant cultivars of muskmelon. Crop Science 51, 810-817.

Edelstein, M., Bradford, K.J. and Burger, D.W. (2001) Metabolic heat and $\mathrm{CO}_{2}$ production rates during germination of melon (Cucumis melo L.) seeds measured by microcalorimetry. Seed Science Research 11, 265-272.

Egli, D.B. (1998) Seed biology and the yield of grain crops. New York, CAB International.
Ellis, R.H. and Roberts, E.H. (1981) The quantification of aging and survival in orthodox seeds. Seed Science $\mathcal{E}$ Technology 9, 373-409.

El-Maarouf-Bouteau, H. and Bailly, C. (2008) Oxidative signaling in seed germination and dormancy. Plant Signaling and Behavior 3, 175-182.

Esashi, Y., Sakai, Y. and Ushizawa, R. (1981) Cyanidesensitive and cyanide-resistant respiration in the germination of cocklebur seeds. Plant Physiology 67, 503-508.

Ferguson, J.M., TeKrony, D.M. and Egli, D.B. (1990) Changes during early seed and axes deterioration: I. Seed quality and mitochondrial respiration. Crop Science 30, 175-179.

Finch-Savage, W.E. (2004) The use of population-based threshold models to describe and predict the effects of seedbed environment on germination and seedling emergence of crops. pp 51-95 in Benech-Arnold, R. and Sanchez, R.A. (Eds) Handbook of seed physiology. Applications to agriculture. New York, Food Products Press.

Finch-Savage, W.E. and Bassel, G.W. (2016) Seed vigour and crop establishment: extending performance beyond adaptation. Journal of Experimental Botany 67, 567-591.

Finch-Savage, W.E. and Leubner-Metzger, G. (2006) Seed dormancy and the control of germination. New Phytologist 171, 501-523.

Footitt, S. and Cohn, M.A. (1995) Seed dormancy in red rice (Oryza sativa) IX. Embryo fructose-2,6-bisphosphate during dormancy breaking and subsequent germination. Plant Physiology 107, 1365-1370.

Forcella, F., Benech-Arnold, R.L., Sanchez, R.A. and Ghersa, C.M. (2000) Modeling seedling emergence. Field Crops Research 67, 123-139.

Frey, T.G. and Mannella, C.A. (2000) The internal structure of mitochondria. Trends in Biochemical Sciences 25, 319-324.

Fu, Y.-B., Ahmed, Z. and Diederichsen, A. (2015) Towards a better monitoring of seed ageing under ex situ seed conservation. Conservation Physiology 3, cov026.

Garcia-Huidobro, J., Monteith, J.L. and Squire, G.R. (1982) Time, temperature and germination of pearl-millet (Pennisetum typhoides S \& H). 1. Constant temperature. Journal of Experimental Botany 33, 288-296.

Groot, S.P.C. and Karssen, C.M. (1987) Gibberellins regulate seed germination in tomato by endosperm weakening: a study with gibberellin-deficient mutants. Planta 171, 525-531.

Groot, S.P.C. and Karssen, C.M. (1992) Dormancy and germination of abscisic acid-deficient tomato seeds. Studies with the sitiens mutant. Plant Physiology 99, 952-958.

Grundy, A.C. (2003) Predicting weed emergence: a review of approaches and future challenges. Weed Research 43, 1-11.

Gummerson, R.J. (1986) The effect of constant temperatures and osmotic potentials on the germination of sugar beet. Journal of Experimental Botany 37, 729-741.

Hardegree, S.P., Walters, C.T., Boehm, A.R., Olsoy, P.J., Clark, P.E. and Pierson, F.B. (2015) Hydrothermal germination models: comparison of two data-fitting approaches with probit optimization. Crop Science 55, 2276-2290.

Hay, F.R., Mead, A. and Bloomberg, M. (2014) Modelling seed germination in response to continuous variables: use and limitations of probit analysis and alternative approaches. Seed Science Research 24, 165-186.

Hourmant, A. and Pradet, A. (1981) Oxidative phosphorylation in germinating lettuce seeds (Lactuca sativa) during the first hours of imbibition. Plant Physiology 68, 631-635.

Huang, Z., Liu, S., Bradford, K.J., Huxman, T.E. and Venable, D.L. (2015) The contribution of germination 
functional traits to population dynamics of a desert plant community. Ecology 97, 250-261.

ISTA (2010) International rules for seed testing. Bassersdorf, Switzerland, International Seed Testing Association.

Joosen, R.V.L., Kodde, J., Willems, L.A.J., Ligterink, W., van der Plas, L.H.W. and Hilhorst, H.W.M. (2010) GERMINATOR: a software package for high-throughput scoring and curve fitting of Arabidopsis seed germination. Plant Journal 62, 148-159.

Kebreab, E. and Murdoch, A.J. (1999) Modelling the effects of water stress and temperature on germination rate of Orobanche aegyptiaca seeds. Journal of Experimental Botany 50, 655-664.

Khan, A.A. and Zeng, G.W. (1985) Dual action of respiratory inhibitors - inhibition of germination and prevention of dormancy induction in lettuce seeds. Plant Physiology 77, 817-823.

Kodde, J., Buckley, W.T., de Groot, C.C., Retiere, M., Zamora, A.M.V. and Groot, S.P.C. (2012) A fast ethanol assay to detect seed deterioration. Seed Science Research $22,55-62$.

Lenoir, C., Corbineau, F. and Côme, D. (1986) Barley (Hordeum vulgare) seed dormancy as related to glumella characteristics. Physiologia Plantarum 68, 301-307.

Logan, D.C., Millar, A.H., Sweetlove, L.J., Hill, S.A. and Leaver, C.J. (2001) Mitochondrial biogenesis during germination in maize embryos. Plant Physiology 125, 662-672.

Matthews, S. and Powell, A. (2011) Towards automated single counts of radicle emergence to predict seed and seedling vigor. Seed Testing International 142, 44-48.

Matthews, S., Noli, E., Demir, I., Khajeh-Hosseini, M. and Wagner, M.H. (2012) Evaluation of seed quality: from physiology to international standardization. Seed Science Research 22, S69-S73.

McDonald, M.B. (1999) Seed deterioration: physiology, repair and assessment. Seed Science \& Technology 27, 177-237.

Meyer, S.E. and Allen, P.S. (2009) Predicting seed dormancy loss and germination timing for Bromus tectorum in a semi-arid environment using hydrothermal time models. Seed Science Research 19, 225-239.

Money, N.P. (1989) Osmotic-pressure of aqueous polyethylene glycols - relationship between molecularweight and vapor-pressure deficit. Plant Physiology 91, 766-769.

Ni, B.R. and Bradford, K.J. (1992) Quantitative models characterizing seed germination responses to abscisic acid and osmoticum. Plant Physiology 98, 1057-1068.

Ni, B.R. and Bradford, K.J. (1993) Germination and dormancy of abscisic acid-deficient and gibberellin-deficient mutant tomato (Lycopersicon esculentum) seeds. Sensitivity of germination to abscisic acid, gibberellin, and water potential. Plant Physiology 101, 607-617.

Nonogaki, H. (2014) Seed dormancy and germination emerging mechanisms and new hypotheses. Frontiers in Plant Science 5, 233.

Nonogaki, H., Chen, F. and Bradford, K.J. (2007) Mechanisms and genes involved in germination sensu stricto. pp. 264-304 in Bradford, K.J.; Nonogaki, H. (Eds) Seed development, dormancy and germination. Oxford, UK, Blackwell Publishing.

Patane, C. and Avola, G. (2013) A seed respiration-based index of cold-sensitivity during imbibition in four macrothermal species. Acta Physiologiae Plantarum 35, 911-918.

Podrabsky, J.E. and Hand, S.C. (2015) Physiological strategies during animal diapause: lessons from brine shrimp and annual killifish. Journal of Experimental Biology 218, 1897-1906.

Ribas-Carbo, M., Taylor, N.L., Giles, L., Busquets, S., Finnegan, P.M., Day, D.A., Lambers, H., Medrano, H., Berry, J.A. and Flexas, J. (2005) Effects of water stress on respiration in soybean leaves. Plant Physiology 139, 466-473.

Roach, D.A. and Wulff, R.D. (1987) Maternal effects in plants. Annual Review of Ecology and Systematics 18, 209-235.

Roberts, E.H. (1973) Predicting the storage life of seeds. Seed Science $\mathcal{E}$ Technology 1, 499-514.

Rodbard, D. (1973) Theory of hormone-receptor interaction. III. The endocrine target cell as a quantal response unit: a general control mechanism. Advances in Experimental Medicine and Biology 36, 342-364.

Ross, H.A. and Hegarty, T.W. (1979) Sensitivity of seed germination and seedling radicle growth to moisture stress in some vegetable crop species. Annals of Botany 43, 241-243.

Rutzke, C.F.J., Taylor, A.G. and Obendorf, R.L. (2008) Influence of aging, oxygen, and moisture on ethanol production from cabbage seeds. Journal of the American Society for Horticultural Science 133, 158-164.

Stein, E.M. and Shakarchi, R. (2003) Fourier analysis: an introduction. Princeton, NJ, Princeton University Press.

Still, D.W. and Bradford, K.J. (1997) Endo-beta-mannanase activity from individual tomato endosperm caps and radicle tips in relation to germination rates. Plant Physiology 113, 21-29.

Tarquis, A.M. and Bradford, K.J. (1992) Prehydration and priming treatments that advance germination also increase the rate of deterioration of lettuce seeds. Journal of Experimental Botany 43, 307-317.

Trewavas, A.J. (2012) Information, noise and communication: thresholds as controlling elements in development. pp. 11-35 in Witzany, G.; Baluska, F. (Eds) Biocommunication of plants. Signaling and communication in plants, vol. 14. Berlin, Springer-Verlag.

Trewavas, A.J. (2014) Plant behaviour and intelligence. Oxford, UK, Oxford University Press.

Van Asbrouck, J. and Taridno, P. (2009) Using the single seed oxygen consumption measurement as a method of determination of different seed quality parameters for commercial tomato seed samples. Asian Journal of Food $\mathcal{E}$ Agro-Industry 2, S88-S95.

Van Duijn, A. and Konig, J. (2001) Measuring metabolic rate changes. Patent 2001 EP1134583 (A1) WO0169243 (A1) US2004033575 (A1) CA2403253 (A1) DE60108480T.

Walters, C. (1998) Understanding the mechanisms and kinetics of seed aging. Seed Science Research 8, 223-244.

Walters, C., Wheeler, L.M. and Grotenhuis, J.M. (2005) Longevity of seeds stored in a genebank: species characteristics. Seed Science Research 15, 1-20.

Watt, M.S., Bloomberg, M. and Finch-Savage, W.E. (2011) Development of a hydrothermal time model that accurately characterises how thermoinhibition regulates seed germination. Plant, Cell E Environment 34, 870-876.

Weitbrecht, K., Müller, K. and Leubner-Metzger, G. (2011) First off the mark: early seed germination. Journal of Experimental Botany 62, 3289-3309.

Woodstock, L.W. (1973) Physiological and biochemical tests for seed vigor. Seed Science and Technology 1, 127-157.

Woodstock, L.W. and Grabe, D.F. (1967) Relationships between seed respiration during imbibition and subsequent seedling growth in Zea mays L. Plant Physiology 42, 1071-1076. 
Xin, X., Tian, Q., Yin, G.K., Chen, X.L., Zhang, J.M., Ng, S. and Lu, X.X. (2014) Reduced mitochondrial and ascorbate-glutathione activity after artificial ageing in soybean seed. Journal of Plant Physiology 171, 140-147.

Zhao, G.-W. and Zhong, T.-L. (2012) Improving the assessment method of seed vigor in Cunninghamia lanceolata and Pinus massoniana based on oxygen sensing technology. Journal of Forestry Research 23, 95-101.

Zhao, G.W., Cao, D.D., Chen, H.Y., Ruan, G.H. and Yang, M.J. (2013) A study on the rapid assessment of conventional rice seed vigour based on oxygen-sensing technology. Seed Science E Technology 41, 257-269. 